\title{
Modeling of Mercuric Chloride Removal in Ductwork and Fabric Filter by Raw Activated Carbon Injection
}

\author{
Vishnu Sriram, Zhouyang Liu, Joo-Youp Lee \\ Chemical Engineering Program, Department of Biomedical, Chemical and Environmental \\ Engineering, University of Cincinnati, Cincinnati, OH 45221-0012
}

*Corresponding author

Dr. Joo-Youp Lee

Chemical Engineering Program, Department of Biomedical, Chemical and Environmental Engineering, University of Cincinnati, Cincinnati, Ohio 45221-0012

Tel: +1(513) 556-0018; Fax: +1(413) 556-0018; E-mail: joo.lee@uc.edu 


\begin{abstract}
Based on previous experimental adsorption kinetic and equilibrium data for mercuric chloride $\left(\mathrm{HgCl}_{2}\right)$ adsorption onto raw activated carbon (AC), a comprehensive model was formulated for its removal in the ductwork and fabric filter by raw AC injection in coal combustion flue gas. Various factors that can impact the performance and sorbent utilization were investigated, including inlet $\mathrm{HgCl}_{2}$ concentration, sorbent loading, particle size, external and internal mass-transfer considerations, residence time, filtration time, injection mode, and pressure drop. Despite these considerations, in-flight removal of $\mathrm{HgCl}_{2}$ in the ductwork was found to be almost negligible. For the removal in fabric filter, the effect of particle size was found to be significant, particularly for continuous sorbent injection. On the other hand, a discontinuous injection mode delivering the same amount of sorbent in $10 \%$ of a cleaning cycle resulted in higher removal performance and sorbent utilization. However, at the end of the cleaning cycle, most of the sorbent capacity was not used $(<0.2 \%)$. The pressure drop across the filter cake built by fly ash and sorbent was found to be manageable within typical operating limits.
\end{abstract}

Keywords: Sorbent injection, $\mathrm{HgCl}_{2}$ adsorption, in-flight capture, fabric filter, external mass transfer, internal mass transfer 


\section{Introduction}

The recent Mercury and Air Toxic Standard (MATS) rule limits the emissions of mercury (Hg) from power plants across the United States.[1] Under the MATS rule, the U.S. Environmental Protection Agency (U.S. EPA) started to reduce the mercury emissions from coal-fired power plants in 2015. Existing electric utility generating units (EGU) would limit their emissions below 0.18-18.14 g/GWh while newer EGUs would have stricter standards of limiting their emissions below 0.04-18.14 $\mathrm{g} / \mathrm{GWh}$ depending on the type of fuel the EGU utilizes.[2] Activated carbon injection has shown promise in controlling gaseous mercury emissions in the particulate matter control devices (PMCDs).[3-4] Previous model results suggest that the removal of oxidized mercury $(\mathrm{Hg}(2+))$ in an entrained flow, using powdered activated carbon (PAC) sorbent is insignificant due to the mass-transfer resistance associated with the sorbent and its short residence time.[5-6] It was also demonstrated through the U.S. Department of Energy's (U.S. DOE) Field Test Program that the in-flight removal of mercury vapor with short residence times was insignificant.[7] In contrast, the removal of mercury in the PMCDs such as fabric filter (FF) and electrostatic precipitator (ESP) was reported to be significant.[6-8]

It has been reported that raw activated carbon (AC) does not physically adsorb elemental mercury $(\mathrm{Hg}(0))$ vapor in a typical post-combustion temperature window (e.g. $\left.60-170{ }^{\circ} \mathrm{C}\right) .[5-9]$ Halogenated AC has shown good potential to increase the removal of both $\operatorname{Hg}(0)$ and $\operatorname{Hg}(2+)$ species.[10-11] However, little has been reported about the capture performance of each mercury species by AC sorbent in terms of the physical and chemical properties of AC such as surface area, porosity, reactions kinetics, and adsorption kinetics and equilibrium. Since a typical mercury concentration in coal combustion flue gas is on the order of ppb, a minimum AC 
sorbent to mercury mass ratio must be much higher than its stoichiometric ratio (e.g., >10,000:1) to achieve $>90 \%$ removal with a typical AC sorbent of a 20- $\mu$ m diameter.[12-13] However, it is also difficult to find previous systematic studies about the effects of sorbent particle size, surface area, pore diameter and adsorption equilibrium and kinetics that can greatly impact on mercury capture performances in the ductwork and PMCDs.

Depending on a level of coal combustion, some unburned carbon remains in fly ash often as a consequence of low- $\mathrm{NO}_{\mathrm{x}}$ combustion systems. It has been reported that the mercury removal performances by fly ash carbons greatly vary with respect to various parameters such as surface area, carbon content, chlorine content in coal, coal types, surface functionalities on carbon.[14-16] One of the previous studies predicted that $<5 \%$ of mercury could be adsorbed by unburned carbon fly ash.[15] Despite the wide performance variations, there is a consensus that the adsorption capacity of fly ash carbons are generally limited. A previous study reported that the capacity for $\mathrm{HgCl}_{2}$ is $\sim 10$ times smaller than that of raw AC.[14-17]

In this study, the removal of mercuric chloride $\left(\mathrm{HgCl}_{2}\right)$ as a model oxidized mercury species in the ductwork and fabric filter using a raw AC sorbent (i.e. Norit America's DARCOHG) has been systematically studied by taking into account the physical parameters of the raw AC sorbent, the physical adsorption equilibrium and kinetics for $\mathrm{HgCl}_{2}$, inlet $\mathrm{HgCl}_{2}$ concentrations, sorbent injection loadings, and external/internal mass transfer. The impacts of these considerations on capture performances in the ductwork and filter cake are demonstrated. A consideration of the pressure drop across the filter cake is also presented for the sorbent injection in a typical range of fly ash loadings. Previous studies have shown the effects of flue gas constituents on the adsorption capacity of $\mathrm{HgCl}_{2}$ onto activated carbon.[18-19] $\mathrm{SO}_{2}$ was reported to have a negative effect on the sorption as it reacts with basic sites on $\mathrm{AC}$. $\mathrm{HCl}$ helped 
in increasing the sorption capacity while $\mathrm{NO}_{2}$ helped in promoting the negative effect of $\mathrm{SO}_{2}$ on the sorption capacity of $\mathrm{HgCl}_{2}$ onto carbon. However, these effects have not been quantified for the adsorption of $\mathrm{HgCl}_{2}$ and thus have not considered in this study.

\section{Kinetic Model for $\mathrm{HgCl}_{2}$ Adsorption onto Raw AC}

\subsection{Model assumptions}

Physical adsorption is considered a main mechanism for $\mathrm{HgCl}_{2}$ adsorption onto raw $\mathrm{AC}$ for sorbent injection after air preheater at $\sim 120-160{ }^{\circ} \mathrm{C}$.[19] The adsorption kinetics was based on the Langmuir theory for this study as the experimental adsorption kinetic data best fit this theory.[20-21] In a post-combustion entrained flow after sorbent injection, the adsorption of $\mathrm{HgCl}_{2}$ onto sorbents comprises of mainly three steps: (1) the external mass transfer of bulk phase $\mathrm{HgCl}_{2}$ to the outer surface of the sorbent; (2) the internal mass transfer due to pore diffusion inside the sorbent particle; and (3) the surface adsorption of $\mathrm{HgCl}_{2}$ onto the inner pore surface of the sorbent. In this study, the adsorption of $\mathrm{HgCl}_{2}$ onto $\mathrm{AC}$ sorbent has been modeled using the following assumptions:

1) The flue gas in the ductwork and filter cake follows plug flow;

2) The axial diffusion is negligible;

3) The sorbent particles are spherical in shape and have a uniform particle size;

4) The adsorption process is isothermal since $\mathrm{HgCl}_{2}$ is present in trace amounts;

5) The properties of the sorbent used are constant; and

6) The adsorption of $\mathrm{HgCl}_{2}$ on the inner walls of the ductwork is negligible. 


\subsection{Model equations}

\subsubsection{In-flight model}

The intrinsic $\mathrm{HgCl}_{2}$ adsorption kinetic expression is given by the Langmuir theory in eq.

1. All of the symbols used in the equations are summarized in the nomenclature section.

$$
r_{A}=\rho_{p} \frac{d q}{d t}=\rho_{p}\left(k_{1}\left(q_{\max }-q\right) C-k_{2}\left(=\frac{k_{1}}{K}\right) q\right)
$$

At equilibrium $\left(r_{A}=0\right)$, the kinetic rate expression leads to the following Langmuir isotherm.

$$
q^{*}=q_{\max } \frac{K C^{*}}{1+K C^{*}}
$$

The two parameters of $\left(q_{\max }\right)$ and $\mathrm{K}$ obtained from the Langmuir isotherm given in eq. 2 are used in the Langmuir kinetic expression shown in eq. 1.

A shell mole balance is formulated to describe the adsorption of $\mathrm{HgCl}_{2}$ inside the sorbent particle. The expression is given as

$$
\varepsilon_{p} \frac{\partial C}{\partial t}=\frac{1}{r^{2}} \frac{\partial}{\partial r}\left(r^{2} D_{e} \frac{\partial C}{\partial r}\right)-r_{A}
$$

The local adsorption rate given in eq. 1 is coupled with the adsorption kinetic expression in eq. 3 in order to calculate the concentration of $\mathrm{HgCl}_{2}$ inside the pore.

Then a mole balance inside the ductwork is taken to describe the in-flight adsorption of $\mathrm{HgCl}_{2}$ in an entrained flow as shown in eq. 4.

$$
\frac{\partial C_{B}}{\partial t}=-r_{A, o b s} \frac{m_{A C}}{\rho_{p}}
$$


The observed adsorption rate expression at the external surface of the sorbent $\left(r=R_{P}\right)$ is calculated by taking a volume average of the local $\mathrm{HgCl}_{2}$ adsorption rate inside the pores over the entire sorbent particle. This expression is denoted as

$$
r_{A, b s}=\left.\frac{3}{R_{p}} D_{e} \frac{\partial C}{\partial r}\right|_{\left(r=R_{p}, t\right)}
$$

Then the observed adsorption rate is coupled with the mole balance in eq. 4 to predict the bulk-phase $\mathrm{HgCl}_{2}$ concentration.

The set of eqns. (1), (3), and (4) has the following initial conditions (ICs) and boundary conditions (BCs).

Initial conditions (ICs):

$$
q(r, t=0)=0 ; C(r, t=0)=0 ; C_{B}(t=0)=C_{B}^{\text {in }}
$$

Boundary conditions (BCs):

$$
\left.\frac{\partial q}{\partial r}\right|_{(r=0, t)}=0 ;\left.\frac{\partial C}{\partial r}\right|_{(r=0, t)}=0 ;\left.\frac{\partial C}{\partial r}\right|_{\left(r=R_{p}, t\right)}=\frac{k_{g}}{D_{e}}\left(C_{B}(t)-C\left(r=R_{p}, t\right)\right)
$$

By solving the coupled governing equations comprised of eqns. (1), (3), (4) with ICs and BCs in eqns. (6) and (7), the profiles of $\mathrm{q}(\mathrm{r}, \mathrm{t}), \mathrm{C}(\mathrm{r}, \mathrm{t})$ and $\mathrm{C}_{\mathrm{B}}(\mathrm{t})$ can be obtained.

The governing equations (eqns. (1), (3), (4)), and the ICs and BCs given in eqns. (6) and (7) are normalized with the following dimensionless variables.

$$
\gamma \equiv \frac{C}{C_{B}^{i n}} ; \gamma_{B} \equiv \frac{C_{B}}{C_{B}^{i n}} ; \varphi \equiv \frac{q}{q_{\max }} ; \xi \equiv \frac{r}{R_{p}} ; \tau^{\prime} \equiv \frac{t}{\frac{\varepsilon_{p} R_{p}^{2}}{D_{e}}}
$$

The normalized governing equations with the ICs and BCs are given in eqns. (9)-(13).

$$
\frac{\partial \varphi}{\partial \tau^{\prime}}=\frac{\varepsilon_{p} R_{p}^{2}}{D_{e}}\left[k_{1}(1-\varphi) \gamma C_{B}^{i n}-k_{2}\left(=\frac{k_{1}}{K}\right) \varphi\right]
$$




$$
\begin{gathered}
\xi^{2} \frac{\partial \gamma}{\partial \tau^{\prime}}=\frac{\partial}{\partial \xi}\left(\xi^{2} \frac{\partial \gamma}{\partial \xi}\right)-\frac{\rho_{p} \xi^{2} q_{\max } R_{p}^{2}}{D_{e} C_{B}^{i n}}\left[k_{1}(1-\varphi) \gamma C_{B}^{i n}-k_{2}\left(=\frac{k_{1}}{K}\right) \varphi\right] \\
\frac{\partial \gamma_{B}}{\partial \tau^{\prime}}=-\left.\frac{3 m_{A C} \varepsilon_{p}}{\rho_{p}} \frac{\partial \gamma}{\partial \xi}\right|_{\left(\xi=1, \tau^{\prime}\right)}
\end{gathered}
$$

ICs

$$
\varphi\left(\xi, \tau^{\prime}=0\right)=0 ; \gamma\left(\xi, \tau^{\prime}=0\right)=0 ; \gamma_{B}\left(\tau^{\prime}=0\right)=1
$$

BCs

$$
\left.\frac{\partial \varphi}{\partial \xi}\right|_{\left(\xi=0, \tau^{\prime}\right)}=0 ;\left.\frac{\partial \gamma}{\partial \xi}\right|_{\left(\xi=0, \tau^{\prime}\right)}=0 ;\left.\frac{\partial \gamma}{\partial \xi}\right|_{\left(\xi=1, \tau^{\prime}\right)}=\frac{k_{g} R_{p}}{D_{e}}\left(\gamma_{B}\left(\tau^{\prime}\right)-\gamma\left(\xi=1, \tau^{\prime}\right)\right)
$$

\subsubsection{Filter cake model}

A detailed description about our filter cake model is given in our previous study.[22] The dimensionless normalized variables, governing equations, and ICs and BCs used in the filter cake model are given in eqns. (14)-(19).

$$
\begin{gathered}
\gamma \equiv \frac{C}{C_{B}^{i n}} ; \gamma_{B} \equiv \frac{C_{B}}{C_{B}^{i n}} ; \varphi \equiv \frac{q}{q_{\max }} ; \xi \equiv \frac{r}{R_{p}} ; \tau \equiv \frac{u}{L_{F}} t ; \lambda \equiv \frac{z}{L_{F}} \\
\frac{\partial \varphi}{\partial \tau}=\frac{L_{F}}{u}\left[k_{1}(1-\varphi) \gamma C_{B}^{i n}-k_{2}\left(=\frac{k_{1}}{K}\right) \varphi\right] \\
\frac{\varepsilon_{p} u \xi^{2} R_{p}^{2}}{L_{F} D_{e}} \frac{\partial \gamma}{\partial \tau}=\frac{\partial}{\partial \xi}\left(\xi^{2} \frac{\partial \gamma}{\partial \xi}\right)-\frac{\rho_{p} \xi^{2} q_{\max } R_{p}^{2}}{D_{e} C_{B}^{i n}}\left[k_{1}(1-\varphi) \gamma C_{B}^{i n}-k_{2}\left(=\frac{k_{1}}{K}\right) \varphi\right] \\
\varepsilon_{b} \frac{\partial \gamma_{B}}{\partial \tau}+\frac{\partial \gamma_{B}}{\partial \lambda}=-\left.\frac{3\left(1-\varepsilon_{b}\right) D_{e} L_{F}}{R_{p}^{2} u} \frac{m_{A C}}{m_{A s h}+m_{A C}} \frac{\partial \gamma}{\partial \xi}\right|_{(\lambda, 1, \tau)}
\end{gathered}
$$

ICs:

$$
\varphi(\lambda, \xi, \tau=0)=0 ; \gamma(\lambda, \xi, \tau=0)=0 ; \gamma_{B}(\lambda, \tau=0)=0
$$

BCs: 


$$
\left.\frac{\partial \varphi}{\partial \xi}\right|_{(\lambda, \xi=0, \tau)}=0 ;\left.\frac{\partial \gamma}{\partial \xi}\right|_{(\lambda, \xi=0, \tau)}=0 ;\left.\frac{\partial \gamma}{\partial \xi}\right|_{(\lambda, \xi=1, \tau)}=\frac{k_{g} R_{p}}{D_{e}}\left(\gamma_{B}(\lambda, \tau)-\gamma(\lambda, \xi=1, \tau)\right) ; \gamma_{B}\left(\lambda=\frac{L(\tau)}{L_{F}}, \tau\right)=1
$$

Darcy's law is used to express the pressure drop across the filter cake. The pressure drop is given as the sum of two terms, one of which is related to the clean filter medium, $\Delta P_{f}$, while the other one is related to the dust cake itself, $\Delta P_{C} \cdot[23]$

$$
\Delta P=\Delta P_{f}+\Delta P_{c}
$$

The pressure drop across the clean fabric is given by

$$
\Delta P_{f}=S_{E} \times V
$$

where $S_{E}$ is the resistance due to the fabric and $\mathrm{V}$ is gas velocity. The pressure drop due to the dust is given by

$$
\Delta P_{c}=K_{2} \times C_{i} \times V^{2} \times t
$$

where $K_{2}$ is the specific cake coefficient; $C_{i}$ is the inlet dust concentration; and t is filtration time. The $\Delta P_{c}$ term is especially important as it is generally larger in magnitude than the first term, $\Delta P_{f} . K_{2}$ depends on the type of a dust, mean particle diameter of dust and is a measure of how fast the dust accumulates in the filter cake. It is found experimentally.[24]

\subsection{Parameters used in the model}

The $\mathrm{HgCl}_{2}$ adsorption model was applied to DARCO-HG AC sorbent. Table 1 lists the physical properties of the sorbent and diffusion coefficient values. The Langmuir adsorption equilibrium and intrinsic kinetic parameters were obtained from our previous study.[21] Another dataset for the DARCO-G60 AC sorbent reported in a previous study is also shown in Tables 1 
and 2 for a comparison of modeling results.[20] The effective diffusivity inside the pores of the sorbent $\left(D_{e}\right)$ and the gas-phase mass transfer coefficients $\left(k_{g}\right)$ were calculated to be $9.05 \times 10^{-8}$ $\mathrm{m}^{2} / \mathrm{s}$ and $2.12 \mathrm{~m} / \mathrm{s}$, respectively.

To calculate the pressure drop across the filter cake, a dust velocity of $0.02 \mathrm{~m} / \mathrm{s}$ was taken.[23] Typically, activated carbon sorbent loading is $\sim 1-5 \%$ of the fly ash loading.[25] This way, the fly ash loading was calculated to be $10 \mathrm{~g} / \mathrm{m}^{3}$. The value of the specific cake resistance, $\mathrm{K}_{2}$, was calculated to be $1 \times 10^{5} \mathrm{~s}^{-1}\left(=10\right.$ inches of $\left.\mathrm{H}_{2} \mathrm{O} / \mathrm{fpm} /\left(\mathrm{lb} / \mathrm{ft}^{2}\right)\right)$ and $0.63 \times 10^{-8} \mathrm{~s}^{-1}(=6.25$ inches of $\left.\mathrm{H}_{2} \mathrm{O} / \mathrm{fpm} /\left(\mathrm{lb} / \mathrm{ft}^{2}\right)\right)$ based on the dust velocity and the mass mean diameter of fly ash dust of $10 \mu \mathrm{m}$ and $20 \mu \mathrm{m}$, respectively.

\section{Results and Discussion}

The model was solved by using COMSOL Multiphysics (version 4.4). The in-flight $\mathrm{HgCl}_{2}$ removal performance of the sorbent was assessed by using two parameters. The first one was normalized average $\mathrm{HgCl}_{2}$ uptake $\left(q_{\text {avg }} / q_{\max }\right)$ as an indicator for the sorbent utilization. It was calculated by

$$
q_{\text {avg }}(t)=\frac{\left[C_{B}^{\text {in }}-C_{B}(t)\right]}{m_{A C}}
$$

The other performance parameter was $\mathrm{HgCl}_{2}$ removal represented by normalized bulk-phase $\mathrm{HgCl}_{2}$ concentration $\gamma_{B}\left(\tau^{\prime}\right)=\frac{C_{B}(t)}{C_{B}^{i n}}$. In a typical power plant, the in-flight residence time of a sorbent after air preheater is estimated to be $\sim 1.5-2 \mathrm{~s}$ until the sorbent particles are collected at PMCDs.[26] Therefore, in this study, all simulations have been run for $\leq 5 \mathrm{~s}$. 
On the other hand, for the study of $\mathrm{HgCl}_{2}$ capture in a fabric filter, the average $\mathrm{HgCl}_{2}$ uptake was modified for the capture in the filter cake by

$$
q_{\text {avg }}(t)=\frac{\int_{0}^{t}\left(C_{B}^{\text {in }}-C_{B}^{\text {out }}(t)\right) d t}{m_{A C} t}
$$

The normalized $\mathrm{HgCl}_{2}$ concentration at the outlet of the filter cake was determined by

$$
\gamma_{B}(\lambda=0, \tau)=\frac{C_{B}^{\text {out }}(z=0, t)}{C_{B}^{\text {in }}}
$$

The operating conditions listed in Table 3 were selected as a base case and were used to study the effects of different factors. In the base case, a sorbent injection loading of $0.1 \mathrm{~g} / \mathrm{m}^{3}$ was chosen since most power plants cannot allow for the loading greater than $0.16 \mathrm{~g} / \mathrm{m}^{3} \quad(=10$ lb/MMacf).[7]

\subsection{In-flight $\mathrm{HgCl}_{2}$ removal study}

\subsubsection{Effects of sorbent particle size and inlet $\mathrm{HgCl}_{2}$ concentration}

The $\mathrm{HgCl}_{2}$ removal efficiency and sorbent utilization as a function of in-flight residence time for different particle sizes ranging from 10 to $30 \mu \mathrm{m}$ and varying inlet $\mathrm{HgCl}_{2}$ concentrations ranging from $1 \mathrm{ppbv}(=11 \mu \mathrm{g} / \mathrm{dscm})$ to $5 \mathrm{ppbv}(=55 \mu \mathrm{g} / \mathrm{dscm})$ for raw AC sorbent are shown in Figure 2(a) and 2(b), respectively. It is evident that $\mathrm{HgCl}_{2}$ removed in the ductwork is $<\sim 0.5 \%$ up to 5-s residence time for all the particle sizes and inlet $\mathrm{HgCl}_{2}$ concentrations at the baseline sorbent injection loading of $0.1 \mathrm{~g} / \mathrm{m}^{3}$. Although it is difficult to find experimental data obtained for the in-flight removal of $\mathrm{HgCl}_{2}$ under well-controlled settings in the literature, a previous paper taking into account the adsorption kinetics and equilibrium for another PAC sorbent also reported that the removal under similar conditions was negligible.[5] As the sorbent particle size 
increases from 10 to $30 \mu \mathrm{m}$, the internal mass-transfer resistance increases and thus $\mathrm{HgCl}_{2}$ removal efficiency decreases from $\sim 0.5$ to $0.25 \%$. It is seen that a variation in the inlet $\mathrm{HgCl}_{2}$ concentrations does not affect the $\mathrm{HgCl}_{2}$ removal efficiency. This suggests that the external mass-transfer resistance derived from the $\mathrm{HgCl}_{2}$ concentration difference in the bulk gas phase is not critical to $\mathrm{HgCl}_{2}$ removal in the ductwork. Since the sorbent has a very short residence time in the duct, the in-flight capture of $\mathrm{HgCl}_{2}$ is negligible.

From Figure 2(b), it can be seen that the sorbent utilization of DARCO-HG is very small as $\sim<0.005 \%$ of the maximum sorbent capacity was utilized. Although a variation in sorbent particle sizes and inlet $\mathrm{HgCl}_{2}$ concentrations does play a role in the sorbent utilization, these effects are noted insignificant. The sorbent utilization decreases from $\sim 0.0048$ to $0.0026 \%$ with an increase in sorbent particle size from 10 to $30 \mu \mathrm{m}$. The sorbent utilization increases with an increase in the inlet $\mathrm{HgCl}_{2}$ concentration as the sorbent can adsorb more $\mathrm{HgCl}_{2}$.

\subsubsection{Effects of sorbent loading and external/internal mass transfer}

The in-flight $\mathrm{HgCl}_{2}$ removal efficiency and sorbent utilization with respect to sorbent loading and external/internal mass transfer are shown in Figure 2(c) and (d), respectively. Although the removal is insignificant, the effect of sorbent loading is pronounced. When the sorbent loading increases from $0.1 \mathrm{~g} / \mathrm{m}^{3}\left(=6.2 \mathrm{lb} / \mathrm{MMcf}\right.$ ) and $1 \mathrm{~g} / \mathrm{m}^{3}$ (=62 $\mathrm{lb} / \mathrm{MMcf}$ ), the $\mathrm{HgCl}_{2}$ removal efficiency almost proportionally increases from $\sim 0.4 \%$ to $\sim 3.4 \%$.

On the other hand, external mass transfer is found to play an insignificant role as the $\mathrm{HgCl}_{2}$ removal efficiency is almost identical in the presence and absence of an external masstransfer consideration. When external mass-transfer is taken into account, the Ranz and Marshall equation in eq. (26) is used for the mass-transfer coefficient $\left(\mathrm{k}_{\mathrm{g}}\right)$ in eqns. (7) and (13). 


$$
S h=2+0.6\left(\operatorname{Re}_{d}\right)^{1 / 2}(S c)^{1 / 3}
$$

When it is not considered for the case of excluding external mass transfer, the surface concentration was set to the bulk-phase concentration (i.e. $C\left(R_{p}, t\right)=C_{B}(t)$ ). The external masstransfer resistance is found to be insignificant and can thus be ignored.

The role of internal mass transfer comprising pore diffusion and surface adsorption is more pronounced for the in-flight capture. The internal pores provide the surface area and pore volume required for the adsorption and transport of $\mathrm{HgCl}_{2}$ inside $\mathrm{AC}$. When the internal surface area is reduced, the maximum adsorption capacity in the Langmuir adsorption kinetics in eq. (1) is also reduced. The pore size governs the pore diffusion of $\mathrm{HgCl}_{2}$ and determines the effective diffusivity via the Knudsen diffusivity in the model. The pore diffusion of $\mathrm{HgCl}_{2}$ inside DARCO-HG is primarily governed by the Knudsen diffusion. In order to examine the effect of pore diameter and maximum adsorption capacity, the model predictions using DARCO-HG were compared with those using DARCO-G60. The parameters obtained for DARCO-G60 in Tables 1 and 2 were used to predict the $\mathrm{HgCl}_{2}$ removal and sorbent utilization. When the reduced effectivity diffusivity $\left(\mathrm{D}_{\mathrm{eff}}\right)$, maximum adsorption capacity $\left(\mathrm{q}_{\max }\right)$, and adsorption equilibrium constant $(\mathrm{K})$ were used for DARCO-G60, $\mathrm{HgCl}_{2}$ removal decreased from $\sim 0.35 \%$ (DARCO-HG) to $\sim 0.30 \%$ (DARCO-G60) for a short residence time of $5 \mathrm{~s}$ given in Fig. 2(c). The corresponding sorbent utilization in Fig. 2(d) shows that DARCO-G60 is better utilized for the in-flight removal since the maximum adsorption capacity $\left(0.0387 \mathrm{~g} \mathrm{HgCl}_{2} / \mathrm{g}\right.$ sorbent for DARCO-G60) is less than that of higher surface area sorbent $\left(0.055 \mathrm{~g} \mathrm{HgCl}_{2} / \mathrm{g}\right.$ sorbent for DARCO-HG). It is also seen that better sorbent utilization can be achieved at low sorbent loading, high porosity, and no external mass transfer. However, it should be noted that these effects on the in-flight removal is negligible. 


\subsubsection{Effects of particle size, sorbent loading and residence time}

The local $\mathrm{HgCl}_{2}$ concentration profile inside the sorbent as a function of the radius of the particle with different sorbent particle sizes varying from 10 to $30 \mu \mathrm{m}$ and in-flight residence times varying from 2 to $5 \mathrm{~s}$ is shown in Figure 3(a). It is clearly shown that a variation in the residence times from 2 to $5 \mathrm{~s}$ makes almost no difference in the $\mathrm{HgCl}_{2}$ concentrations inside the sorbent with the different particle sizes. This indicates that the residence times are too short to result in different local $\mathrm{HgCl}_{2}$ concentrations inside the sorbent.

Figure 3(b) shows the local $\mathrm{HgCl}_{2}$ concentration profiles with respect to sorbent loading ranging from 0.1 to $1 \mathrm{~g} / \mathrm{m}^{3}$ and residence time varying from 2 to $5 \mathrm{~s}$. The result suggests that even the 10-time difference in the sorbent loadings has an insignificant impact on the local $\mathrm{HgCl}_{2}$ concentration profiles.

\subsection{Fabric filter $\mathrm{HgCl}_{2}$ removal study}

\subsubsection{Effects of sorbent particle size and external/internal mass transfer}

Figure 4(a) and (b) show the $\mathrm{HgCl}_{2}$ removal efficiency and sorbent utilization as a function of filtration time in terms of sorbent particle size, external, and internal mass transfer. The results show that the sorbent particle size plays a major role in $\mathrm{HgCl}_{2}$ removal efficiency on FF. For example, a smaller sorbent with a $10-\mu \mathrm{m}$ diameter shows a $\sim 90 \% \mathrm{HgCl}_{2}$ removal efficiency at 40 min while a larger sorbent with a $30-\mu \mathrm{m}$ diameter shows $\sim 70 \%$ removal. A smaller particle has less resistance to adsorption when compared to a larger sorbent. The result also estimates that it takes $\sim 60 \mathrm{~min}$ to achieve $90 \% \mathrm{HgCl}_{2}$ removal when the sorbent with a $20-$ $\mu \mathrm{m}$ diameter is continuously injected at $0.1 \mathrm{~g} / \mathrm{m}^{3}$. 
The sorbent utilization for a smaller particle is found to be better compared to a larger one. However, it needs to be noted that the adsorption capacity of a small sorbent is small compared to the capacity of the large one. To study the effect of internal mass transfer, two sorbents with different surface areas were compared. The internal pores required for adsorption was found to be an important factor with the smaller surface area sorbent showing lower $\mathrm{HgCl}_{2}$ removal efficiency.

\subsubsection{Effects of sorbent loading and external/internal mass transfer}

The temporal removal of $\mathrm{HgCl}_{2}$ and sorbent utilization with respect to sorbent loading and external/internal mass transfer are shown in Figure 4(c) and (d), respectively. Sorbent loading and filtration time are the most important factors affecting the $\mathrm{HgCl}_{2}$ removal efficiency in FF. As a case study, the $\mathrm{HgCl}_{2}$ removal performances are compared for continuous and discontinuous sorbent injection methods introducing the same amount of the raw $\mathrm{AC}$ sorbent during a cleaning cycle. By injecting a 10-time higher sorbent loading (i.e. $1 \mathrm{~g} / \mathrm{m}^{3}$ ) in $10 \%$ of a cleaning time (i.e. $9 \mathrm{~min}$ ), a $\mathrm{HgCl}_{2}$ removal efficiency of $\sim 90 \%$ can be achieved within the first $10 \%$ of the filtration time. If the same amount of sorbent is used at a lower sorbent loading (i.e.

$0.1 \mathrm{~g} / \mathrm{m}^{3}$ ), the same $\sim 90 \% \mathrm{HgCl}_{2}$ removal can be achieved after $\sim 66 \%$ of the entire filtration time. As shown in Figure 4(d), while a continuous sorbent loading at $0.1 \mathrm{~g} / \mathrm{m}^{3}$ can utilize $\sim 0.15 \%$ of the total adsorption capacity, a discontinuous loading at $1 \mathrm{~g} / \mathrm{m}^{3}$ can achieve $\sim 0.20 \%$.

The role of external mass transfer is also found to be insignificant in FF. This shows that the external mass-transfer resistance estimated by the Ranz and Marshall equation is diffusion limited and insignificant under FF conditions. However, the effect of internal mass transfer is significant as can be seen in Figure 4 (c-d). In the case of discontinuous loading, it is seen that 
$\mathrm{HgCl}_{2}$ removal efficiency decreases after sorbent injection is cut-off for smaller surface area sorbent. This is because the desorption of $\mathrm{HgCl}_{2}$ from the sorbent is significant. This is not evident in DARCO-HG as the equilibrium constant is relatively higher.

\subsubsection{Effects of sorbent particle size and continuous/discontinuous injection}

An additional case study is conducted for continuous and discontinuous injection in terms of sorbent particle size by taking into account external and internal mass transfer. The effect of the sorbent particle size on the removal is much more pronounced for continuous injection as shown in Figure 5(a). When the particle diameter varies from 10 to $30 \mu \mathrm{m}$, the $\mathrm{HgCl}_{2}$ removal efficiency for continuous injection varies noticeably. For example, a $90 \% \mathrm{HgCl}_{2}$ removal efficiency is achieved at $\sim 40 \mathrm{~min}$ for a continuous injection of $10-\mu \mathrm{m}$ particles while it takes $\sim 78$ min to achieve the same $90 \%$ removal with $30-\mu$ m particles. On the other hand, the removal for discontinuous injection is less sensitive to the particle size. This difference is attributed mainly to the sorbent injection loading $\left(\mathrm{m}_{\mathrm{AC}}\right)$ in eq. (17). When discontinuous injection is used, the thick sorbent layer accumulated on the filter cake as a result of high loading during an initial filtration period significantly removes $\mathrm{HgCl}_{2}$, thus leading to less dependence on the particle size.

Figure 5(b) shows better sorbent utilization for continuous injection up to later filtration phase as a result of low continuous loading. However, if longer filtration time is allowable, discontinuous injection shows better utilization. This will be governed by allowable pressure drop across the filter cake, and is discussed in the next section. 


\subsubsection{Pressure drop across the filter cake}

Figure 6 shows the pressure drop across the filter cake in terms of fly ash particle size and cake thickness as a function of filtration time. Typically, fabric filters have an operating pressure drop ranging between $871 \mathrm{~Pa}\left(=3.5\right.$ inches of $\left.\mathrm{H}_{2} \mathrm{O}\right)$ and 2,240 $\mathrm{Pa}\left(=9\right.$ inches of $\left.\mathrm{H}_{2} \mathrm{O}\right)$ with an average operating pressure drop of $\sim 1,593 \mathrm{~Pa}\left(=6.4\right.$ inches of $\left.\mathrm{H}_{2} \mathrm{O}\right)$.[23] In practice, a typical sorbent loading is $\sim 1-5 \%$ of fly ash loading and a typical fly ash loading is $\sim 10 \mathrm{~g} / \mathrm{m}^{3}$.[25] Using Darcy's law, the pressure drop can be estimated for the filter cake. The particle size distribution of fly ash is reported to range from $5 \mu \mathrm{m}$ to as big as $100 \mu \mathrm{m}$ with an average particle size of $\sim 10-20 \mu \mathrm{m}$ comparable to the size of raw AC.[27] Therefore, in this study, the pressure drop is estimated using fly ash particles with 10 - and $20-\mu \mathrm{m}$ diameters injected at 10 $\mathrm{g} / \mathrm{m}^{3}$. As shown in Figure 6, the pressure drop is sensitive to the particle size. For a dust diameter of $10 \mu \mathrm{m}$, an average cleaning cycle based on the average pressure drop could be close to $\sim 70$ min while for $20-\mu \mathrm{m}$ dust particles, an average cleaning cycle can last up to $90 \mathrm{~min}$, which is used in this study. The filter cake thickness was estimated to be $\sim 1.5 \mathrm{~mm}$ for a filtration time of $90 \mathrm{~min}$.

\section{Conclusions}

A detailed case study on the adsorption of $\mathrm{HgCl}_{2}$ by DARCO-HG sorbent was performed. The modeling results showed that the in-flight capture of $\mathrm{HgCl}_{2}$ was almost negligible with an $\mathrm{HgCl}_{2}$ removal efficiency of $\sim<0.5 \%$ at $140{ }^{\circ} \mathrm{C}$. The sorbent utilization was $<0.005 \%$ of the maximum adsorption capacity of the raw AC. Among the parameters studied, high sorbent loading, maximum adsorption capacity (as a driving force for adsorption kinetics) and residence time were found to play a role in $\mathrm{HgCl}_{2}$ removal efficiency. However, there seems to be no 
practical solution to increase mercury removal in the ductwork. Most $\mathrm{HgCl}_{2}$ removal could be achieved in fabric filter. For the removal in FF, particle size significantly influenced the removal performance for continuous injection whereas it did not show an advantage for discontinuous injection using the same amount of sorbent over the same cleaning cycle. The sizable filter cake thickness promptly piled from discontinuous injection could compensate for the sensitivity of particle size. Most pressure drop across the filter cake was derived from fly ash loading and size, which can determine the cleaning cycle and sorbent loading required to meet the performance goal.

\section{Acknowledgements}

This study was supported by the National Science Foundation, NSF CAREER Grant \# 1151017, and Ohio Development Service Agency, Grant Agreement \# OER-CDO-D-14-21. The authors appreciate their financial support. The authors appreciate Norit Americas, Inc. providing a DARCO-HG activated carbon sample. The authors also appreciate Ms. Carly Kennell for helping us prepare this manuscript.

\section{Nomenclature}

C $\quad \mathrm{HgCl}_{2}$ concentration inside the pore, $\mathrm{g} \mathrm{HgCl}_{2} / \mathrm{m}^{3}$

$C_{B} \quad \mathrm{HgCl}_{2}$ concentration in the bulk gas phase, $\mathrm{g} \mathrm{HgCl}_{2} / \mathrm{m}^{3}$

$C_{B}^{i n}$ inlet $\mathrm{HgCl}_{2}$ concentration in the bulk gas phase, $\mathrm{g} \mathrm{HgCl}_{2} / \mathrm{m}^{3}$

$C_{B}^{\text {out }}$ outlet $\mathrm{HgCl}_{2}$ concentration in the bulk gas phase, $\mathrm{g} \mathrm{HgCl}_{2} / \mathrm{m}^{3}$

$C_{i} \quad$ inlet dust concentration, $\mathrm{lb} / \mathrm{ft}^{3}$ 
$D_{e} \quad$ effective pore diffusion coefficient, $\mathrm{m}^{2} / \mathrm{s}$

$D_{p} \quad$ sorbent particle diameter, $\mathrm{m}$

$K$ equilibrium constant, $\mathrm{K}=\mathrm{k}_{1} / \mathrm{k}_{2}, \mathrm{~m}^{3} / \mathrm{g} \mathrm{HgCl}_{2}$.

$k_{1} \quad$ adsorption rate constant, $\mathrm{m}^{3} /(\mathrm{g} \cdot \mathrm{s})$

$k_{2} \quad$ desorption rate constant, $1 / \mathrm{s}$

$K_{2} \quad$ specific cake coefficient, $1 / \mathrm{s}$

$k_{g} \quad$ gas-phase mass-transfer coefficient, $\mathrm{m} / \mathrm{s}$

$m_{A C} \quad$ sorbent injection loading in flue gas, $\mathrm{g} / \mathrm{m}^{3}$

$m_{\text {Ash }} \quad$ fly ash concentration in flue gas, $\mathrm{g} / \mathrm{m}^{3}$

$L \quad$ filter cake thickness, $m$

$L_{F} \quad$ final cake thickness formed at a final filtration time $\left(t_{F}\right)$

$\Delta P \quad$ pressure drop across the filter cake, $\mathrm{Pa}$

$\Delta P_{c} \quad$ pressure drop due to filter cake, $\mathrm{Pa}$

$\Delta P_{f} \quad$ pressure drop due to filter, $\mathrm{Pa}$

$S_{E} \quad$ residual drag due to fabric, $\mathrm{Pa} /(\mathrm{m} / \mathrm{s})$

$q \quad \mathrm{HgCl}_{2}$ uptake onto sorbent, $\mathrm{g} \mathrm{HgCl}_{2} / \mathrm{g}$ sorbent

$q_{\text {avg }}$ average $\mathrm{HgCl}_{2}$ uptake onto sorbent, $\mathrm{g} \mathrm{HgCl}_{2} / \mathrm{g}_{\text {sorbent }}$

$q_{\max }$ maximum $\mathrm{HgCl}_{2}$ adsorption capacity, $\mathrm{g} \mathrm{HgCl}_{2} / \mathrm{g}$ sorbent

$R_{p} \quad$ radius of sorbent particle, $\mathrm{m}$

$r \quad$ radial distance inside sorbent, $\mathrm{m}$ 


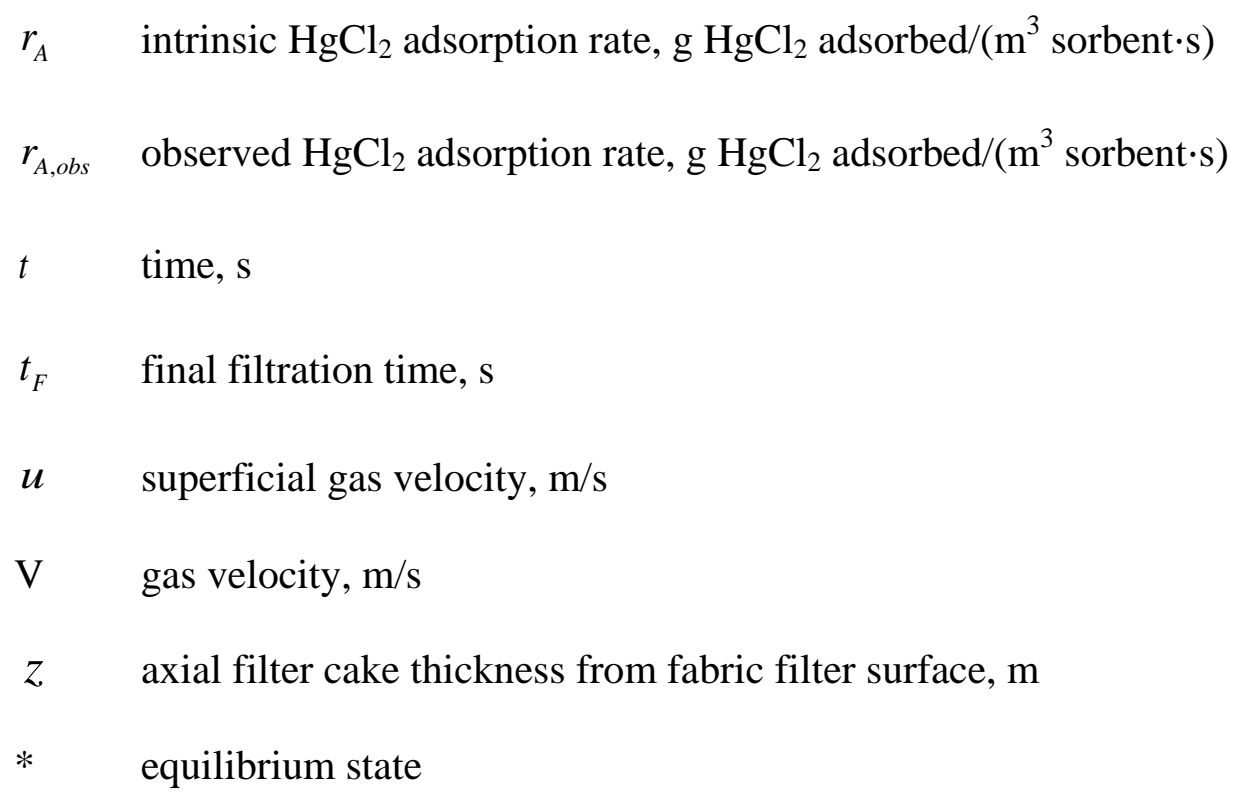

\section{Greek letters}

$\varepsilon_{b} \quad$ bed porosity

$\varepsilon_{p} \quad$ particle porosity

$\rho_{p} \quad$ sorbent particle density, $\mathrm{g} / \mathrm{m}^{3}$

$\varphi \quad$ in-flight dimensionless sorbent uptake, see eq. (8)

$\xi \quad$ in-flight dimensionless radial distance, see eq. (8)

$\gamma \quad$ in-flight dimensionless pore concentration, see eq. (8)

$\gamma_{B}$ in-flight dimensionless bulk concentration, see eq. (8)

$\tau^{\prime} \quad$ in-flight dimensionless time, see eq. (8)

$\varphi \quad$ filter cake dimensionless sorbent uptake, see eq. (14)

$\xi \quad$ filter cake dimensionless radial distance, see eq. (14)

$\lambda \quad$ filter cake dimensionless axial distance, see eq. (14)

$\gamma \quad$ filter cake dimensionless pore concentration, see eq. (14) 
$\gamma_{B} \quad$ filter cake dimensionless bulk concentration, see eq. (14)

$\gamma_{B}^{\text {out }} \quad$ filter cake dimensionless outlet bulk concentration

$\tau \quad$ filter cake dimensionless time, see eq. (14)

\section{References}

[1] Federal Implementation Plans: Interstate Transport of Fine Particulate Matter and Ozone and Correction of SIP Approvals, 40 CFR Parts 51, 52, 72, 78, and 97. EPA US. 2011. p. 48207-712.

[2] National Emission Standards for Hazardous Air Pollutants From Coaland Oil-Fired Electric Utility Steam Generating Units and Standards of Performance for Fossil-Fuel-Fired Electric Utility, Industrial-Commercial Institutional, and Small Industrial Commercial. EPA US. 2016.

[3] Sjostrom S, Bustard J, Durham M, Chang R. Analysis of key parameters impacting mercury control on coal-fired boilers. Proceedings of Air Qual IV Meeting. Arlington, VA, 2003.

[4] Sjostrom S, Ebner T, Slye R, Chang R, Strohfus M, Pelerine J, et al. Full-Scale Evaluation of Mercury Control at Great River Energy’s Stanton Generating Station using Injected Sorbents and a Spray Dryer/Baghouse. Proceedings of Air Qual III Conf. Arlington, VA, 2002. p. 9-12.

[5] Scala F. Simulation of mercury capture by activated carbon injection in incinerator flue gas. 1. In-duct removal. Environ Sci Technol 2001;35(21):4367-72.

[6] Flora JR, Hargis RA, O’Dowd WJ, Pennline HW, Vidic RD. Modeling sorbent injection for mercury control in baghouse filters: I-model development and sensitivity analysis. J Air Waste Manage Assoc 2003;53(4):478-88.

[7] Jones AP, Hoffmann JW, Smith DN, Feeley TJ, Murphy JT. DOE/NETL's Phase II mercury control technology field testing program: preliminary economic analysis of activated carbon injection. Environ Sci Technol 2007;41(4):1365-71. 
[8] Scala F. Simulation of mercury capture by activated carbon injection in incinerator flue gas. 2. Fabric filter removal. Environ Sci Technol 2001;35(21):4373-8.

[9] Srivastava RK, Hutson N, Martin B, Princiotta F, Staudt J. Control of mercury emissions from coal-fired electric utility boilers. Environ Sci Technol 2006;40(5):1385-93.

[10] Nelson S, Landreth R, Zhou Q, Miller J. Accumulated power-plant mercury-removal experience with brominated PAC injection. Proceedings of Jt EPRI DOE EPA Comb. Util. Air Pollut. Control Symp, Mega Symp. Washington, DC, 2004.

[11] Qu Z, Chang JJ, Hsiung T-L, Yan N, Wang HP, Dod R, et al. Halides on carbonaceous materials for enhanced capture of Hg0: mechanistic study. Energy Fuels 2010;24(6):3534-9.

[12] Brown TD, Smith DN, Hargis Jr RA, O'Dowd WJ. Mercury measurement and its control: what we know, have learned, and need to further investigate. J Air Waste Manage Assoc 1999;49(6):1-97.

[13] Pavlish JH, Sondreal EA, Mann MD, Olson ES, Galbreath KC, Laudal DL, et al. Status review of mercury control options for coal-fired power plants. Fuel Process Technol 2003;82(2):89-165.

[14] Senior CL, Johnson SA. Impact of carbon-in-ash on mercury removal across particulate control devices in coal-fired power plants. Energy Fuels 2005;19(3):859-63.

[15] Serre SD, Silcox GD. Adsorption of elemental mercury on the residual carbon in coal fly ash. Ind Eng Chem Res 2000;39(6):1723-30.

[16] Maroto-Valer MM, Zhang Y, Granite EJ, Tang Z, Pennline HW. Effect of porous structure and surface functionality on the mercury capacity of a fly ash carbon and its activated sample. Fuel 2005;84(1):105-8. 
[17] Karatza D, Lancia A, Musmarra D. Fly ash capture of mercuric chloride vapors from exhaust combustion gas. Environ Sci Technol 1998;32(24):3999-4004.

[18] Mibeck BA, Olson ES, Miller SJ. $\mathrm{HgCl} 2$ sorption on lignite activated carbon: Analysis of fixed-bed results. Fuel Process Technol 2009;90(11):1364-71.

[19] Carey TR, Jr OWH, Richardson CF, Chang R, Meserole FB. Factors affecting mercury control in utility flue gas using activated carbon. J Air Waste Manage Assoc 1998;48(12):116674.

[20] Karatza D, Lancia A, Musmarra D, Pepe F, Volpicelli G. Removal of mercuric chloride from flue gas by sulfur impregnated activated carbon. Hazard Waste Hazard Mater 1996;13(1):95-105.

[21] Li X, Liu Z, Lee J-Y. Adsorption kinetic and equilibrium study for removal of mercuric chloride by CuCl2-impregnated activated carbon sorbent. J Hazard Mater 2013;252:419-27.

[22] Li X, Lee J-Y. Modeling of Mercuric Chloride Removal by CuCl2-Impregnated Activated Carbon Sorbent in a Fabric Filter. Energy Fuels 2013;27(12):7654-63.

[23] Davis WT, Buonicore AJ. Air pollution engineering manual. 2nd ed., New York: Wiley; 2000.

[24] Dennis R, Cass R, Cooper D, Hall R, Hampl V. Filtration model for coal fly ash with glass fabrics. 1977.

[25] Sjostrom SM. Activated Carbon Injection. In: Granite EJ, Pennline HW, Senior C, editors. Mercury Control: for Coal-Derived Gas Streams, Weinheim, Germany: Wiley; 2014. p. 293-310. [26] Durham M, Bustard J, Starns T, Sjostrom S, Lindsey C, Martin C, et al. Full-scale evaluation of mercury control by injecting activated carbon upstream of ESPs. Proceedings of Int Conf Air Qual IV. Arlington, VA, 2003. p. 22-4. 
[27] Seames WS. An initial study of the fine fragmentation fly ash particle mode generated during pulverized coal combustion. Fuel Process Technol 2003;81(2):109-25. 


\section{Figure Caption}

Fig. 1. Schematic of post-combustion capture of mercury in a typical coal-fired power plant

Fig. 2. Effects of sorbent particle size and inlet $\mathrm{HgCl}_{2}$ concentration on (a) $\mathrm{HgCl}_{2}$ removal efficiency, (b) sorbent utilization as a function of in-flight residence time, where external and internal mass transfer resistances were considered for all cases (DARCO-HG, $\mathrm{m}_{\mathrm{AC}}=0.1 \mathrm{~g} / \mathrm{m}^{3}, \mathrm{~T}$ $=140^{\circ} \mathrm{C}$ ). Effects of sorbent loading, internal mass transfer (int MT) and external mass transfer (ext MT) on (c) $\mathrm{HgCl}_{2}$ removal efficiency and (d) sorbent utilization as a function of in-flight residence time (DARCO-HG, $\left.\mathrm{C}_{\mathrm{B}}{ }^{\text {in }}=1 \mathrm{ppbv}(=11 \mu \mathrm{g} / \mathrm{dscm}), \mathrm{D}_{\mathrm{p}}=20 \mu \mathrm{m}, \mathrm{T}=140^{\circ} \mathrm{C}\right)$

Fig. 3. (a) Effects of sorbent particle size and in-flight residence time on the $\mathrm{HgCl}_{2}$ concentration inside the sorbent as a function of radius of the particle (DARCO-HG; $\mathrm{C}_{\mathrm{B}}{ }^{\text {in }}, 1 \mathrm{ppbv}(=11$ $\mu \mathrm{g} / \mathrm{dscm}$ ), $\mathrm{m}_{\mathrm{AC}}=0.1 \mathrm{~g} / \mathrm{m}^{3}, \mathrm{~T}=140^{\circ} \mathrm{C}$ ). (b) Effects of sorbent loading and in-flight residence time on the $\mathrm{HgCl}_{2}$ concentration inside the sorbent as a function of radius of the particle (DARCO-HG, $\left.\mathrm{C}_{\mathrm{B}}^{\text {in }}=1 \mathrm{ppbv}(=11 \mu \mathrm{g} / \mathrm{dscm}), \mathrm{D}_{\mathrm{p}}=20 \mu \mathrm{m}, \mathrm{T}=140^{\circ} \mathrm{C}\right)$

Fig. 4. Effects of sorbent particle size and internal (int MT)/external mass transfer (ext MT) on (a) $\mathrm{HgCl}_{2}$ removal efficiency and (b) sorbent utilization for continuous sorbent injection (DARCO-HG, $\left.\mathrm{C}_{\mathrm{B}}{ }^{\mathrm{in}}=1 \mathrm{ppbv}(=11 \mu \mathrm{g} / \mathrm{dscm}), \mathrm{m}_{\mathrm{AC}}=0.1 \mathrm{~g} / \mathrm{m}^{3}, \mathrm{~T}=140{ }^{\circ} \mathrm{C}\right)$. Effects of sorbent loading and internal (int MT)/ external mass transfer (ext MT) on (c) $\mathrm{HgCl}_{2}$ removal efficiency and (d) sorbent utilization for continuous (CI) and discontinuous (DI) sorbent injection $\left(\right.$ DARCO-HG, $\left.\mathrm{C}_{\mathrm{B}}{ }^{\mathrm{in}}=1 \mathrm{ppbv}(=11 \mu \mathrm{g} / \mathrm{dscm}), \mathrm{m}_{\mathrm{AC}}=0.1 \mathrm{~g} / \mathrm{m}^{3}, \mathrm{~T}=140^{\circ} \mathrm{C}\right)$

Fig. 5. Effects of sorbent particle size and loading on (a) $\mathrm{HgCl} 2$ removal efficiency and (b) sorbent utilization when external and internal mass transfers were considered for continuous (CI) 
and discontinuous (DI) sorbent injection (DARCO-HG, $\mathrm{C}_{\mathrm{B}}{ }^{\text {in }}=1 \mathrm{ppbv}(=11 \mu \mathrm{g} / \mathrm{dscm}), \mathrm{T}=140$ $\left.{ }^{\circ} \mathrm{C}\right)$

Fig. 6. Effects of fly ash particle mass-mean diameter (MMD) on pressure drop across the filter cake at fly ash loading of $10 \mathrm{~g} / \mathrm{m}^{3}$ and cake thickness as a function of filtration time for a dust velocity of $0.02 \mathrm{~m} / \mathrm{s}$ 
Table 1. Physical properties of raw AC and diffusivity values used in this study

\begin{tabular}{|c|c|c|c|c|c|c|c|}
\hline Sorbent & $\begin{array}{c}\text { Particle } \\
\mathbf{d e n s i t y}, \boldsymbol{\rho}_{\mathbf{p}} \\
\left(\mathbf{g} / \mathbf{c m}^{\mathbf{3}}\right)\end{array}$ & $\begin{array}{c}\text { BET Surface } \\
\mathbf{a r e a}\left(\mathbf{m}^{\mathbf{2}} / \mathbf{g}\right)\end{array}$ & $\begin{array}{c}\text { Pore volume, } \\
\mathbf{v}_{\mathbf{p}}\left(\mathbf{c m}^{\mathbf{3}} / \mathbf{g}\right)\end{array}$ & $\begin{array}{c}\text { Particle } \\
\text { porosity, } \boldsymbol{\varepsilon}_{\mathbf{p}}\end{array}$ & $\mathbf{d}_{\text {pore }}(\mathbf{n m})$ & $\begin{array}{c}\text { Knudsen } \\
\text { diffusivity } \\
\left(\mathbf{m}^{2} / \mathbf{s}\right)\end{array}$ & $\begin{array}{c}\text { Effective } \\
\mathbf{d i f f u s i v i t y} \\
\left(\mathbf{m}^{\mathbf{2}} / \mathbf{s}\right)\end{array}$ \\
\hline DARCO-HG & 0.950 & 476 & 0.53 & 0.50 & 6.2 & $3.71 \times 10^{-7}$ & $9.05 \times 10^{-8}$ \\
\hline $\begin{array}{c}\text { DARCO- } \\
\text { G60[20] }\end{array}$ & 0.450 & 230 & Not available & 0.60 & 3.7 & $2.21 \times 10^{-7}$ & $7.86 \times 10^{-8}$ \\
\hline
\end{tabular}

Molecular diffusivity $=1.53 \times 10^{-5} \mathrm{~m}^{2} / \mathrm{s}$ 
Table 2. Langmuir adsorption equilibrium and kinetic constants used in this study

\begin{tabular}{|c|c|c|c|c|}
\hline Sorbent & $\begin{array}{c}\mathbf{q}_{\max } \\
\left(\mathbf{g} \mathbf{~ H g C l}_{2} / \mathbf{g}\right. \\
\text { sorbent })\end{array}$ & $\begin{array}{c}\mathbf{K} \\
\left(\mathbf{m}^{\mathbf{3}} / \mathbf{g} \mathbf{H g C l}_{2}\right)\end{array}$ & $\begin{array}{c}\mathbf{k}_{\mathbf{1}} \\
\left(\mathbf{m}^{\mathbf{3}} /(\mathbf{g} \cdot \mathbf{s})\right)\end{array}$ & $\begin{array}{c}\mathbf{k}_{\mathbf{2}} \\
\mathbf{( 1 / s})\end{array}$ \\
\hline DARCO-HG & 0.055 & $2.1 \times 10^{4}$ & 0.2 & $9.5 \times 10^{-6}$ \\
\hline DARCO-G60[20] & 0.0387 & $4.77 \times 10^{2}$ & 0.2 & $4.19 \times 10^{-4}$ \\
\hline
\end{tabular}


Table 3. Base case simulation parameters used for in-flight and fabric filter capture.

\begin{tabular}{|c|c|}
\hline Parameter & Value \\
\hline Inlet $\mathrm{HgCl}_{2}$ concentration & $1 \mathrm{ppbv}(=11 \mu \mathrm{g} / \mathrm{dscm})$ \\
\hline Sorbent injection loading & $0.1 \mathrm{~g} / \mathrm{m}^{3}(=6.2 \mathrm{lb} / \mathrm{MMcf})$ \\
\hline Temperature & $140{ }^{\circ} \mathrm{C}$ \\
\hline Residence time in ductwork for in-flight capture & $5 \mathrm{~s}$ \\
\hline Filtration time for fabric filter capture & $90 \mathrm{mins}$ \\
\hline
\end{tabular}


Fig. 1

Schematic of post-combustion capture of mercury in a typical coal-fired power plant

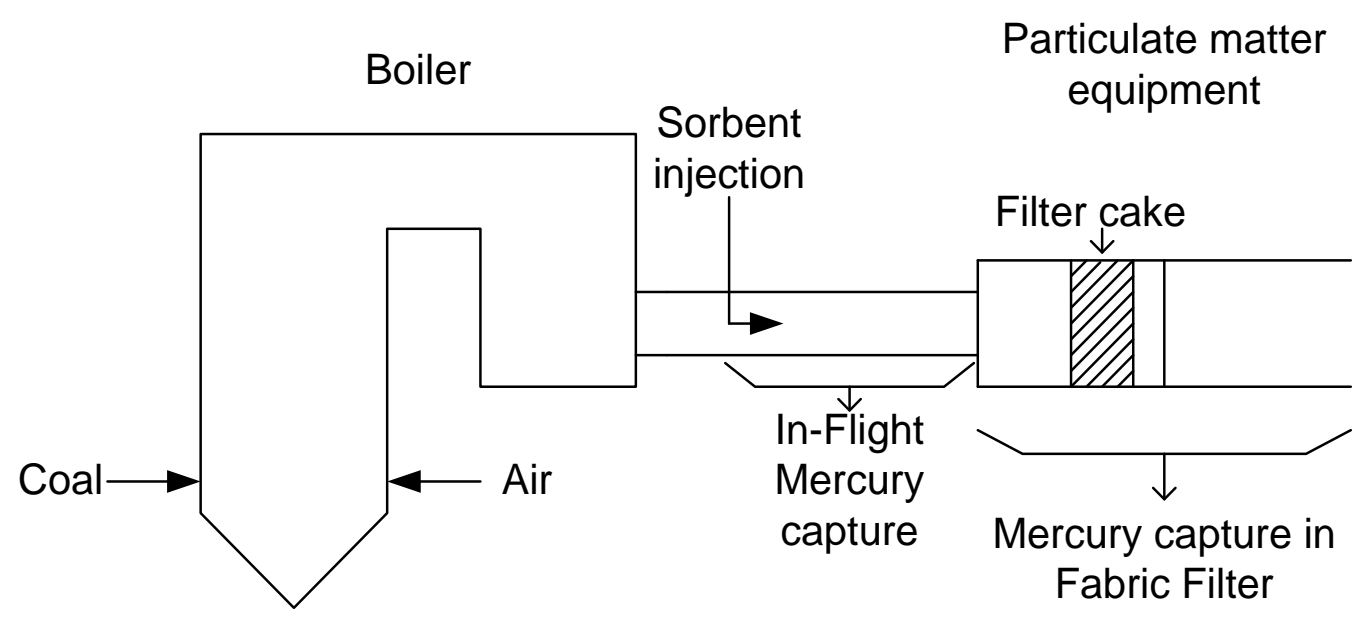


Fig. 2

Effects of sorbent particle size and inlet $\mathrm{HgCl}_{2}$ concentration on (a) $\mathrm{HgCl}_{2}$ removal efficiency, (b) sorbent utilization as a function of in-flight residence time, where external and internal mass transfer resistances were considered for all cases (DARCO-HG, $\mathrm{m}_{\mathrm{AC}}=0.1$ $\mathrm{g} / \mathrm{m}^{3}, \mathrm{~T}=140{ }^{\circ} \mathrm{C}$ ). Effects of sorbent loading, internal mass transfer (int MT) and external mass transfer (ext MT) on (c) $\mathrm{HgCl}_{2}$ removal efficiency and (d) sorbent utilization as a function of in-flight residence time (DARCO-HG, $\mathrm{C}_{\mathrm{B}}{ }^{\text {in }}=1 \mathrm{ppbv}(=11 \mu \mathrm{g} / \mathrm{dscm}), \mathrm{D}_{\mathrm{p}}=20$ $\left.\mu \mathrm{m}, \mathrm{T}=140^{\circ} \mathrm{C}\right)$
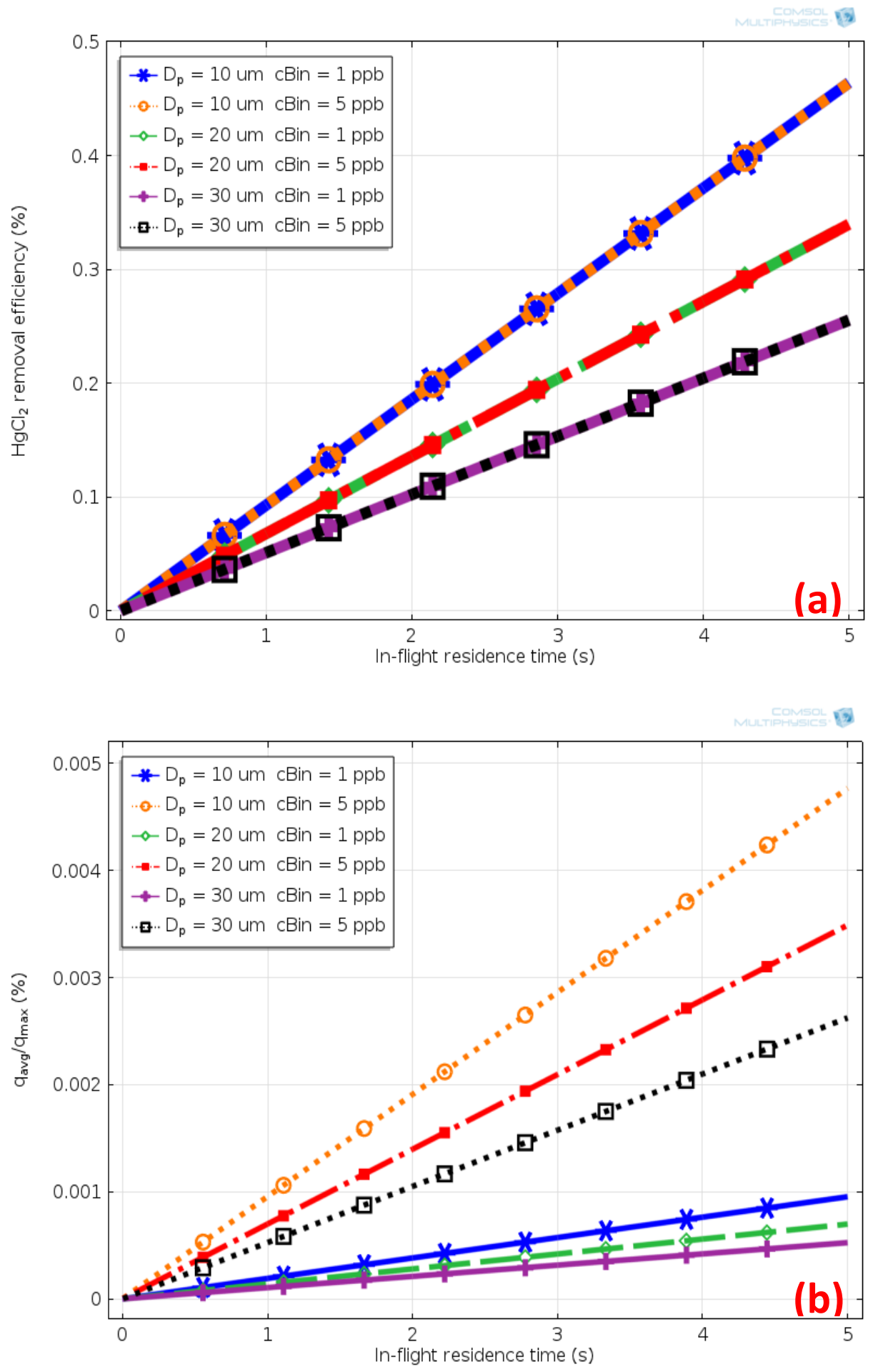

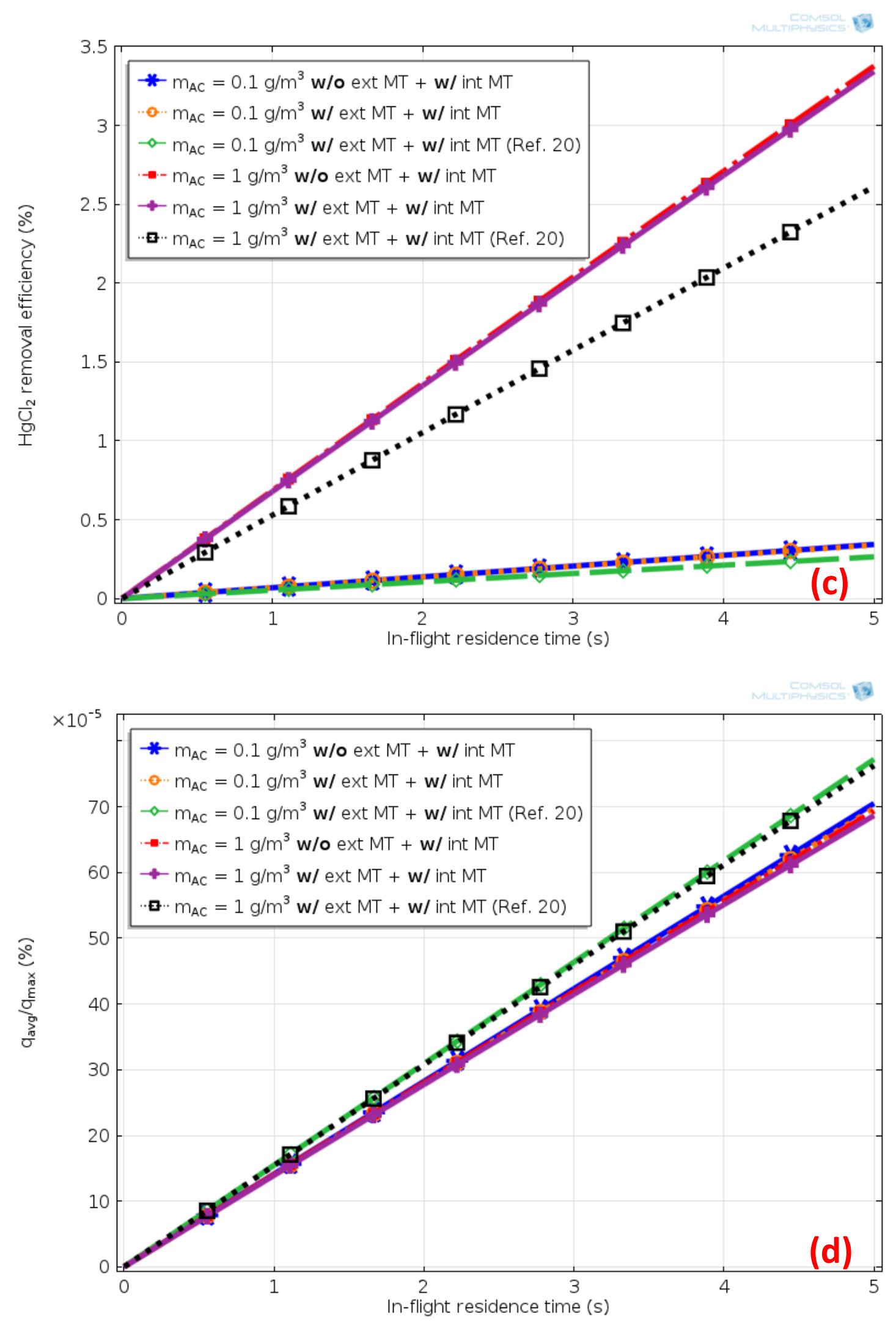
Fig. 3

(a) Effects of sorbent particle size and in-flight residence time on the $\mathrm{HgCl}_{2}$ concentration inside the sorbent as a function of radius of the particle (DARCO-HG; $\mathrm{C}_{\mathrm{B}}{ }^{\text {in }}, 1 \mathrm{ppbv}(=11$ $\mu \mathrm{g} / \mathrm{dscm}$ ), $\mathrm{m}_{\mathrm{AC}}=0.1 \mathrm{~g} / \mathrm{m}^{3}, \mathrm{~T}=140^{\circ} \mathrm{C}$ ). (b) Effects of sorbent loading and in-flight residence time on the $\mathrm{HgCl}_{2}$ concentration inside the sorbent as a function of radius of the particle $\left(\right.$ DARCO-HG, $\left.\mathrm{C}_{\mathrm{B}}{ }^{\text {in }}=1 \mathrm{ppbv}(=11 \mu \mathrm{g} / \mathrm{dscm}), \mathrm{D}_{\mathrm{p}}=20 \mu \mathrm{m}, \mathrm{T}=140{ }^{\circ} \mathrm{C}\right)$
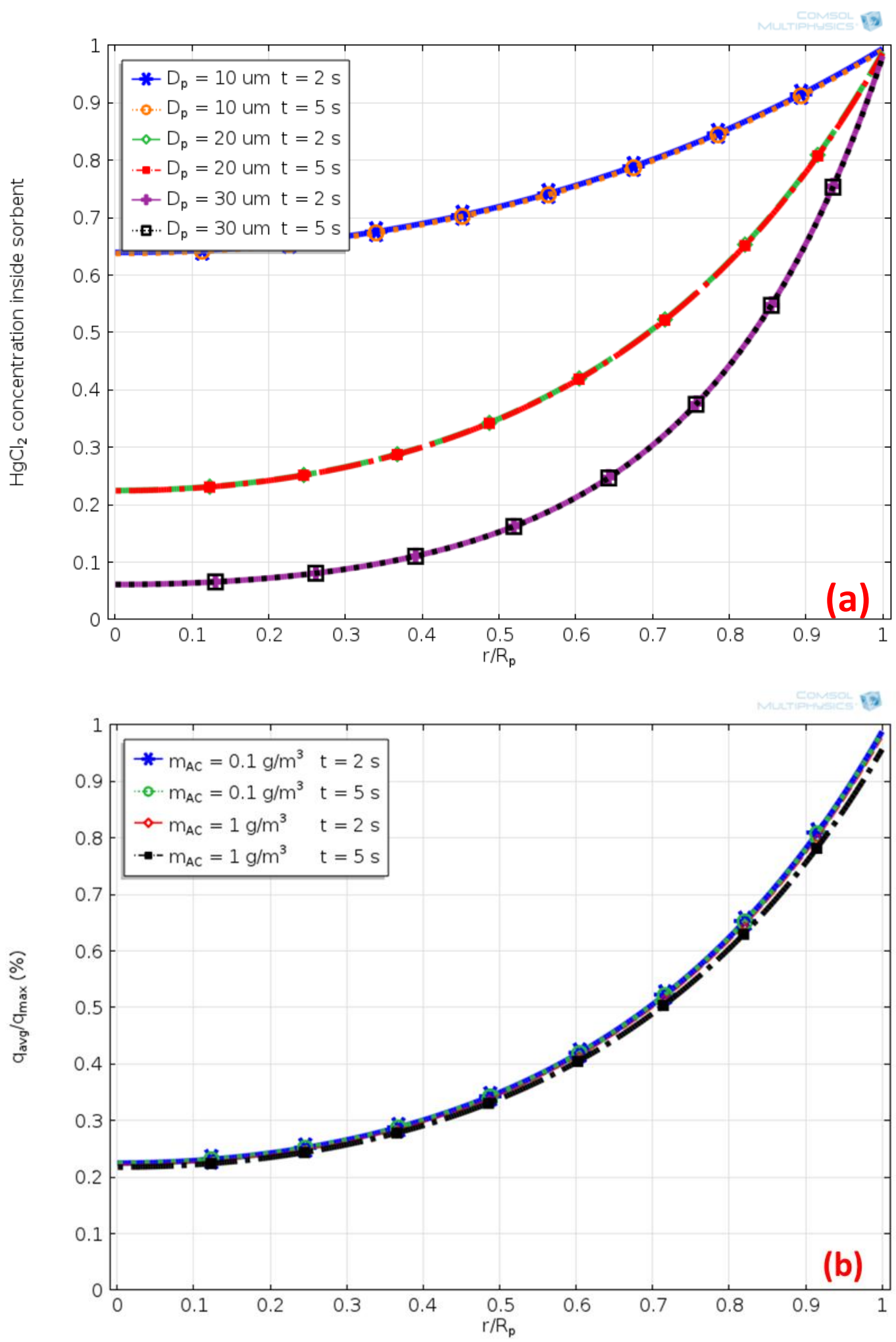
Fig. 4

Effects of sorbent particle size and internal (int MT)/external mass transfer (ext MT) on (a) $\mathrm{HgCl}_{2}$ removal efficiency and (b) sorbent utilization for continuous sorbent injection (DARCO-HG, $\mathrm{C}_{\mathrm{B}}{ }^{\text {in }}=1$ $\left.\operatorname{ppbv}(=11 \mu \mathrm{g} / \mathrm{dscm}), \mathrm{m}_{\mathrm{AC}}=0.1 \mathrm{~g} / \mathrm{m}^{3}, \mathrm{~T}=140^{\circ} \mathrm{C}\right)$. Effects of sorbent loading and internal (int MT)/ external mass transfer (ext MT) on (c) $\mathrm{HgCl}_{2}$ removal efficiency and (d) sorbent utilization for continuous (CI) and discontinuous (DI) sorbent injection (DARCO-HG, $\mathrm{C}_{\mathrm{B}}{ }^{\text {in }}=1 \mathrm{ppbv}(=11$ $\left.\mu \mathrm{g} / \mathrm{dscm}), \mathrm{m}_{\mathrm{AC}}=0.1 \mathrm{~g} / \mathrm{m}^{3}, \mathrm{~T}=140^{\circ} \mathrm{C}\right)$
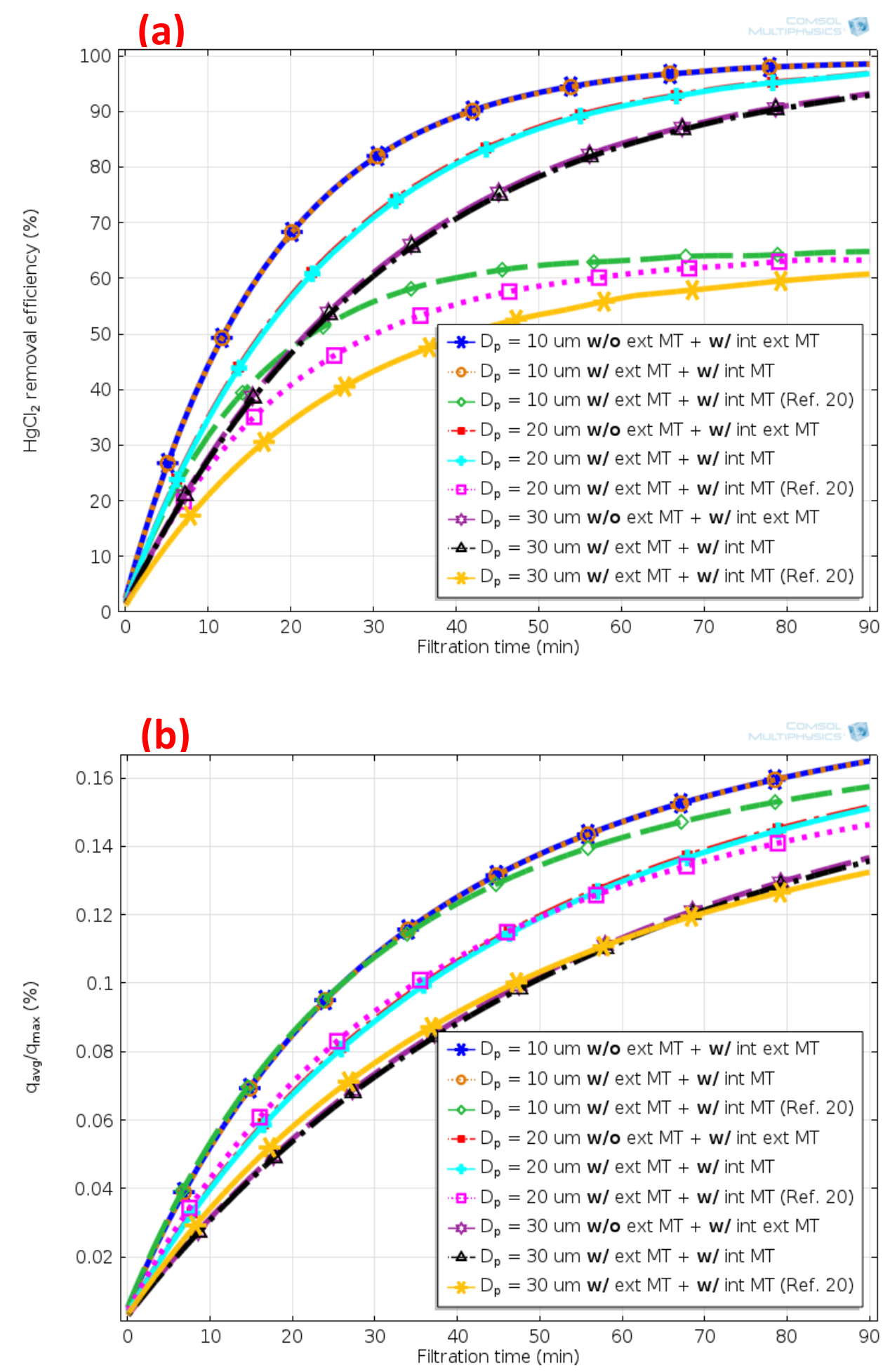

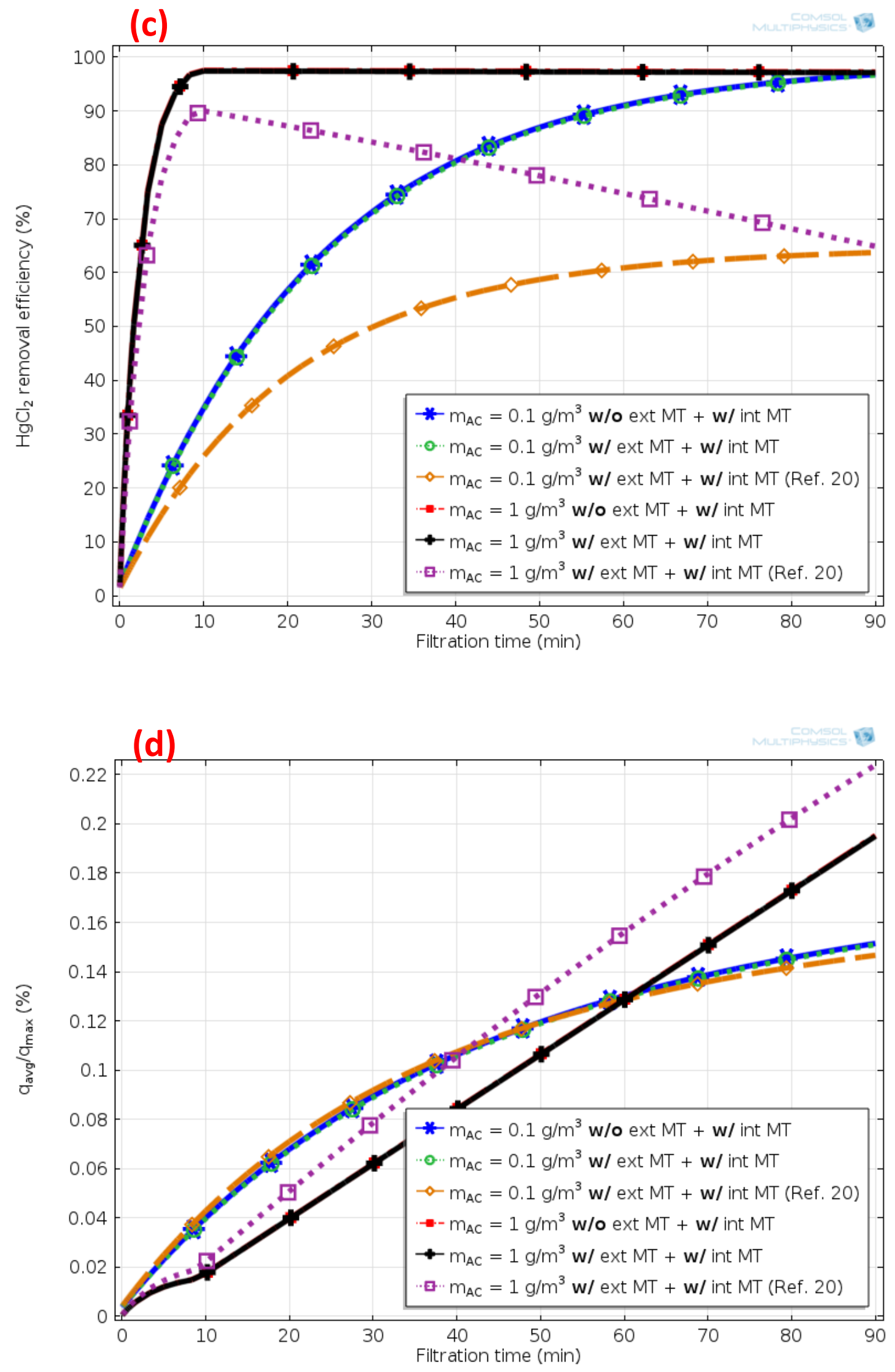
Fig. 5.

Effects of sorbent particle size and loading on (a) $\mathrm{HgCl} 2$ removal efficiency and (b) sorbent utilization when external and internal mass transfers were considered for continuous (CI) and discontinuous (DI) sorbent injection (DARCO-HG, $\mathrm{C}_{\mathrm{B}}{ }^{\text {in }}=1 \mathrm{ppbv}(=11 \mu \mathrm{g} / \mathrm{dscm}$ ), $\mathrm{T}=140$ $\left.{ }^{\circ} \mathrm{C}\right)$
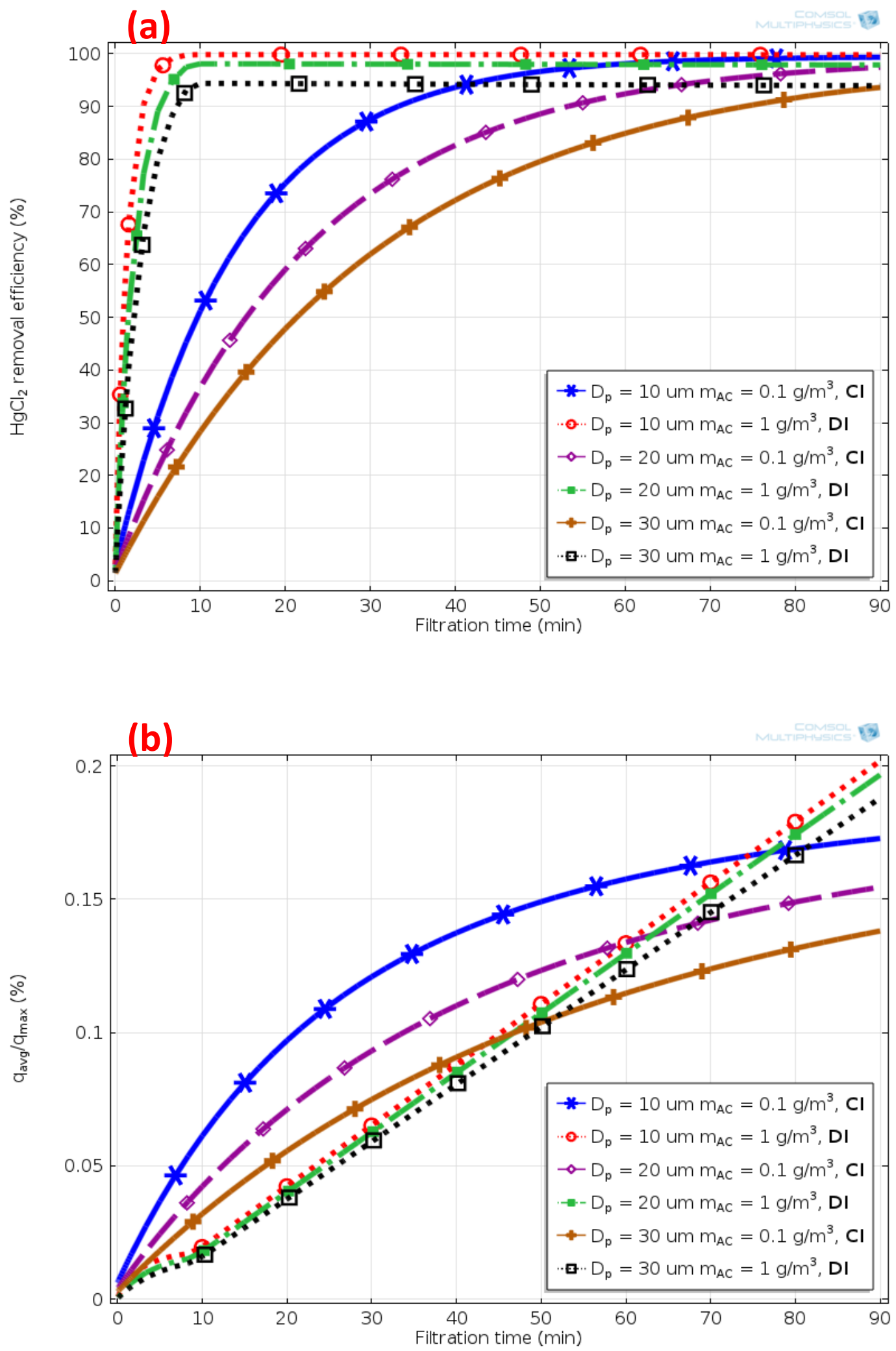
Fig. 6

Effects of fly ash particle mass-mean diameter (MMD) on pressure drop across the filter cake at fly ash loading of $10 \mathrm{~g} / \mathrm{m}^{3}$ and cake thickness as a function of filtration time for a dust velocity of $0.02 \mathrm{~m} / \mathrm{s}$

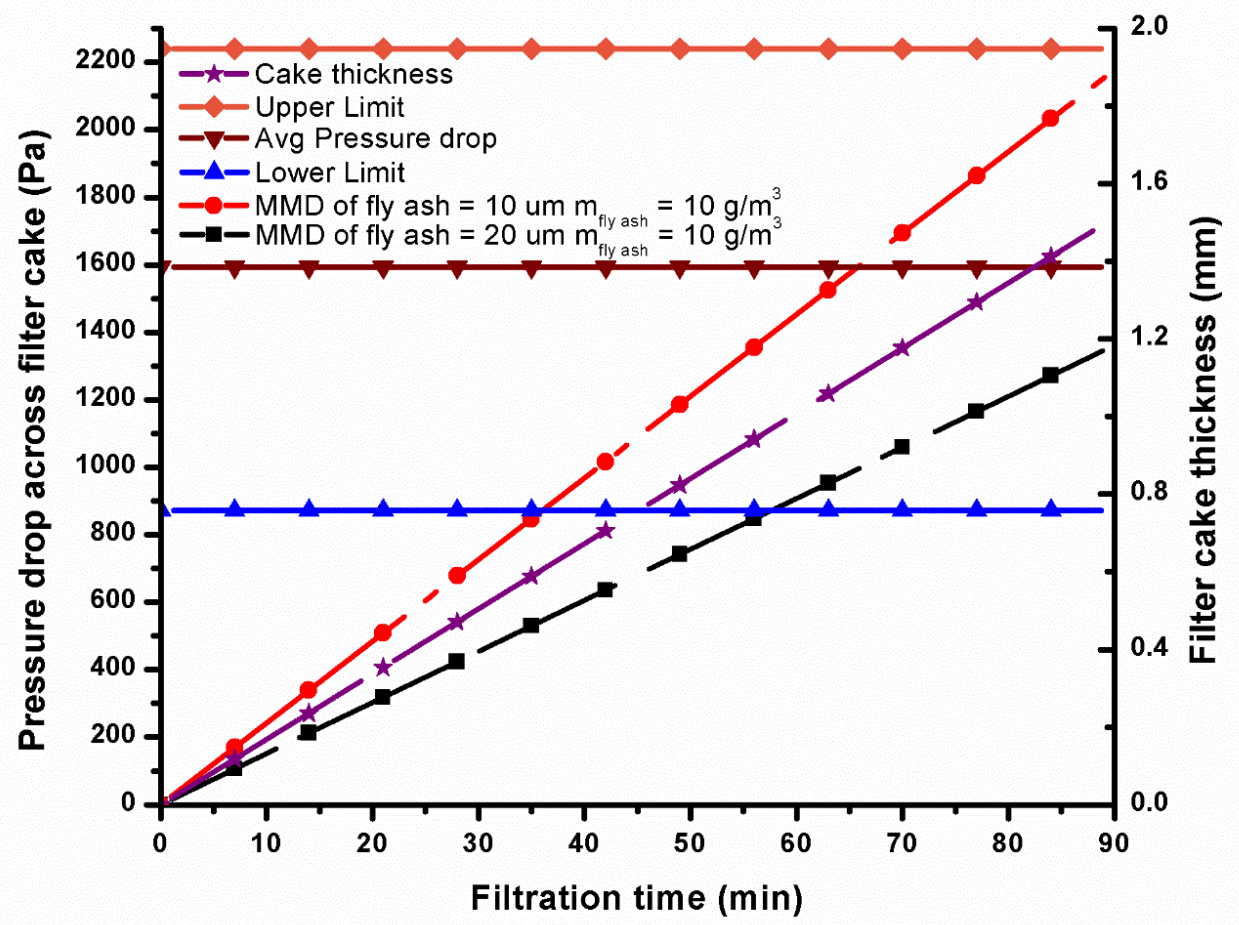




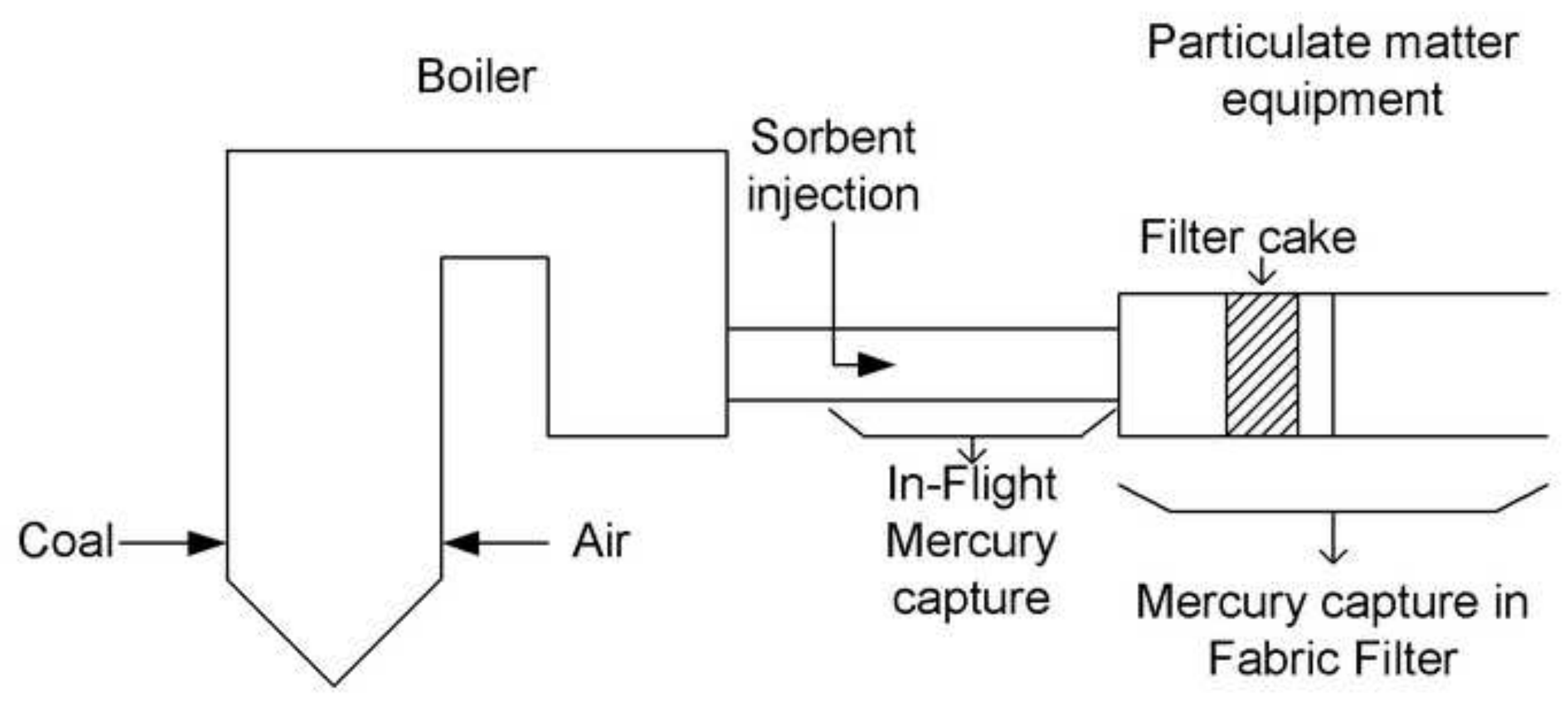


Revised Figure 2
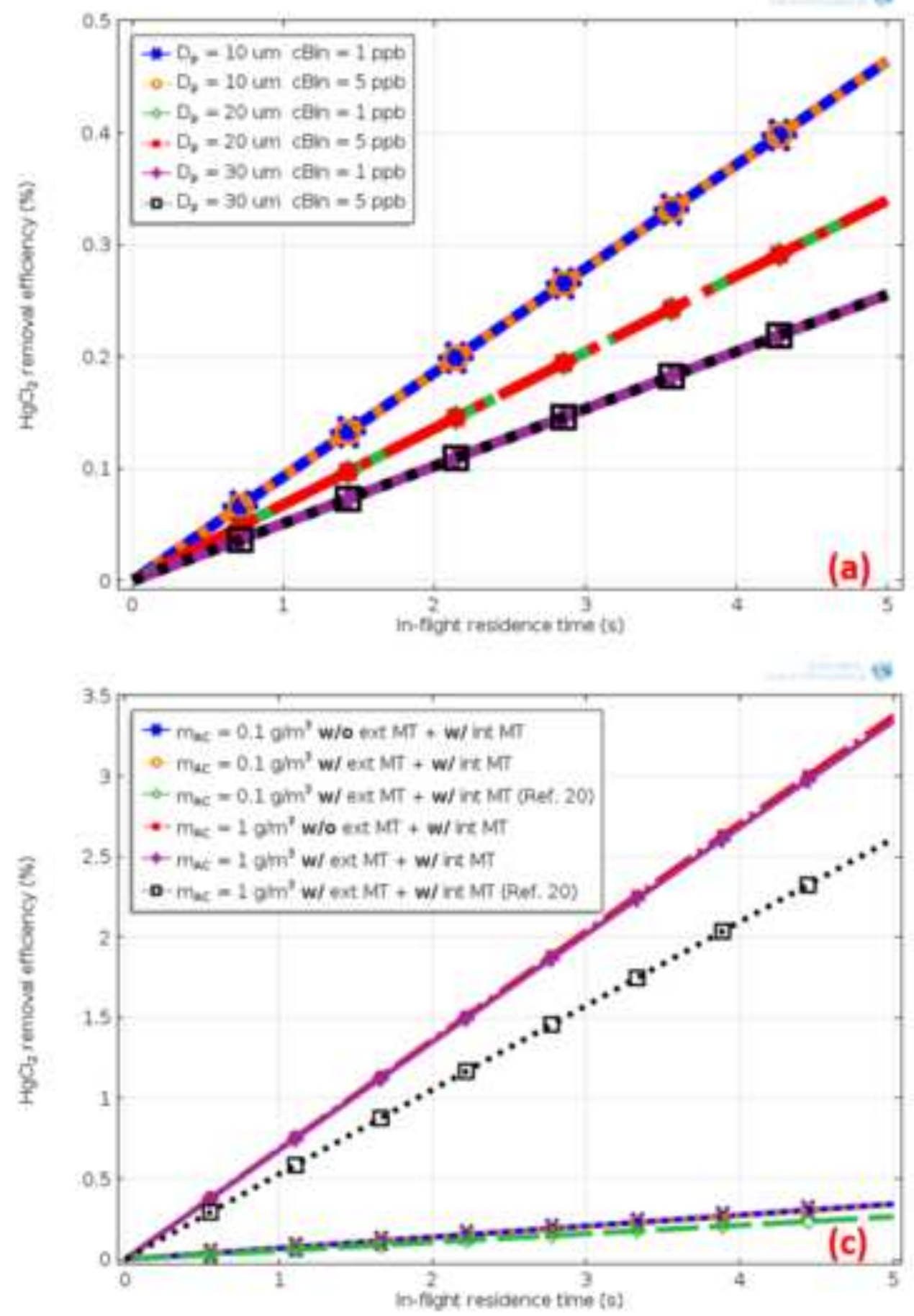

8
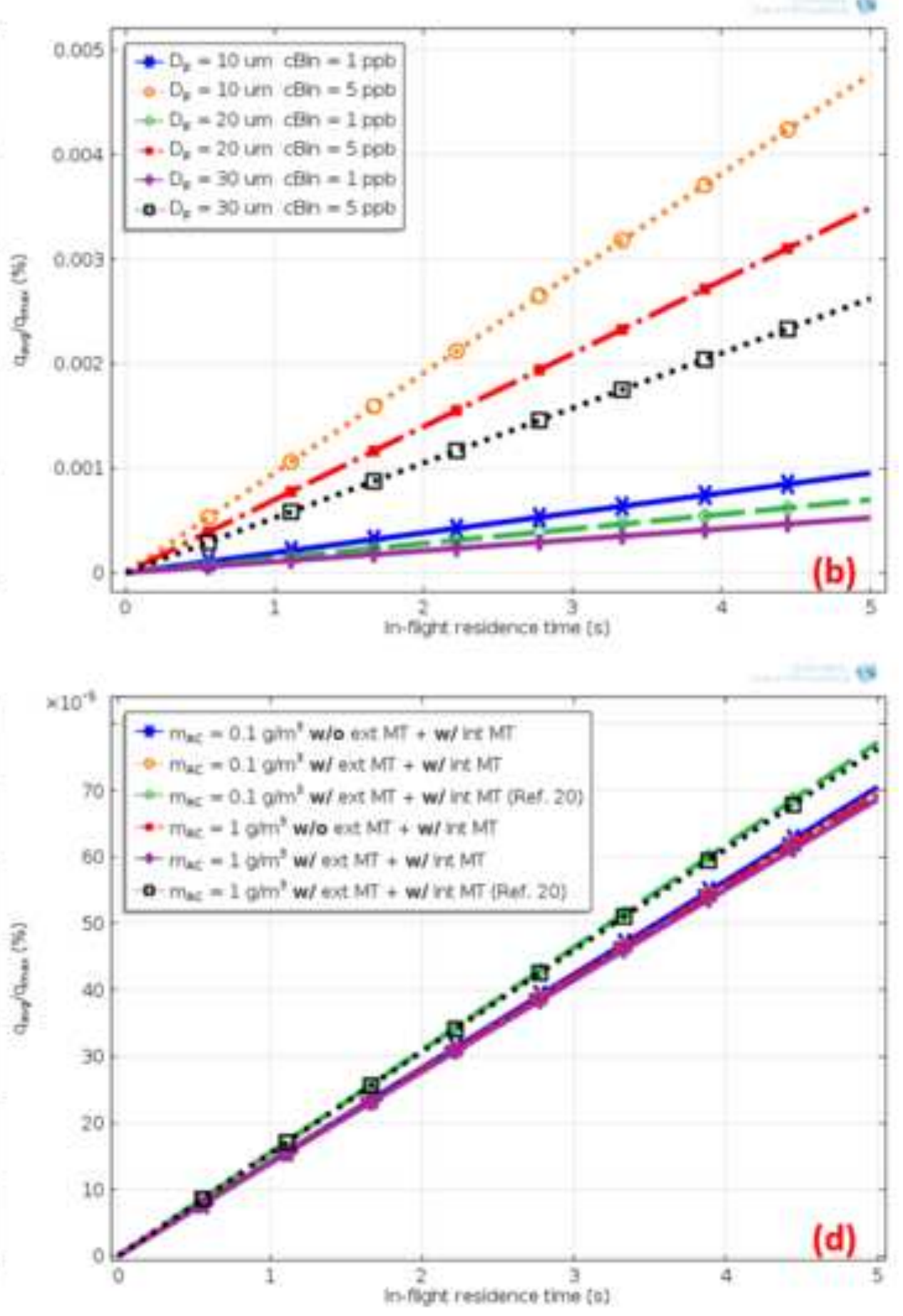
Revised Figure 3
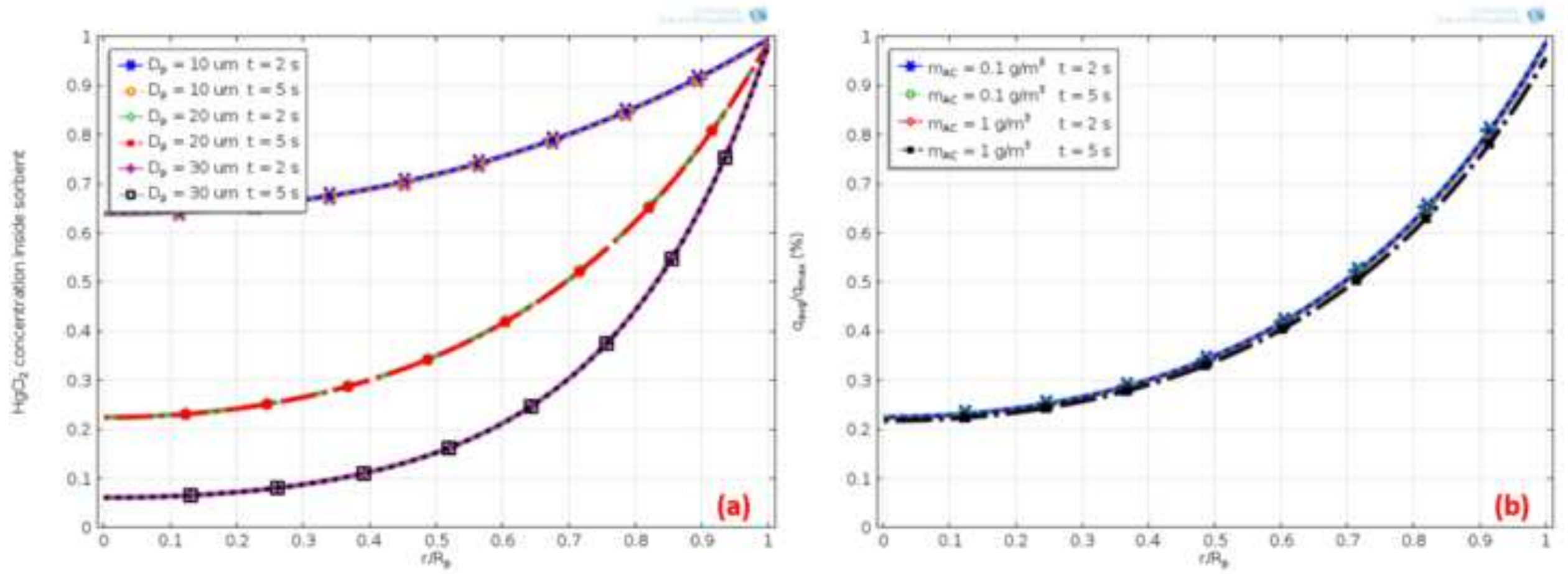
(a)

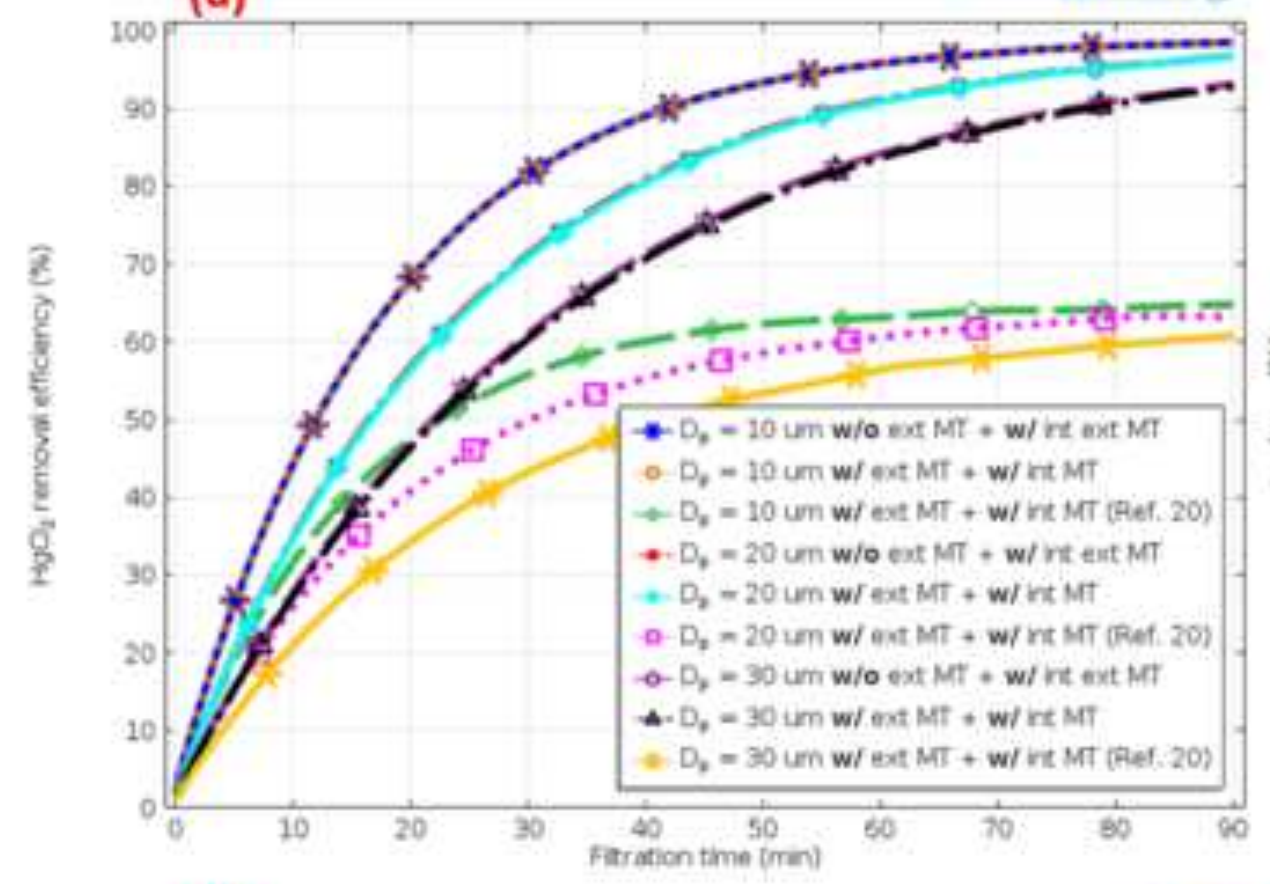

(c)

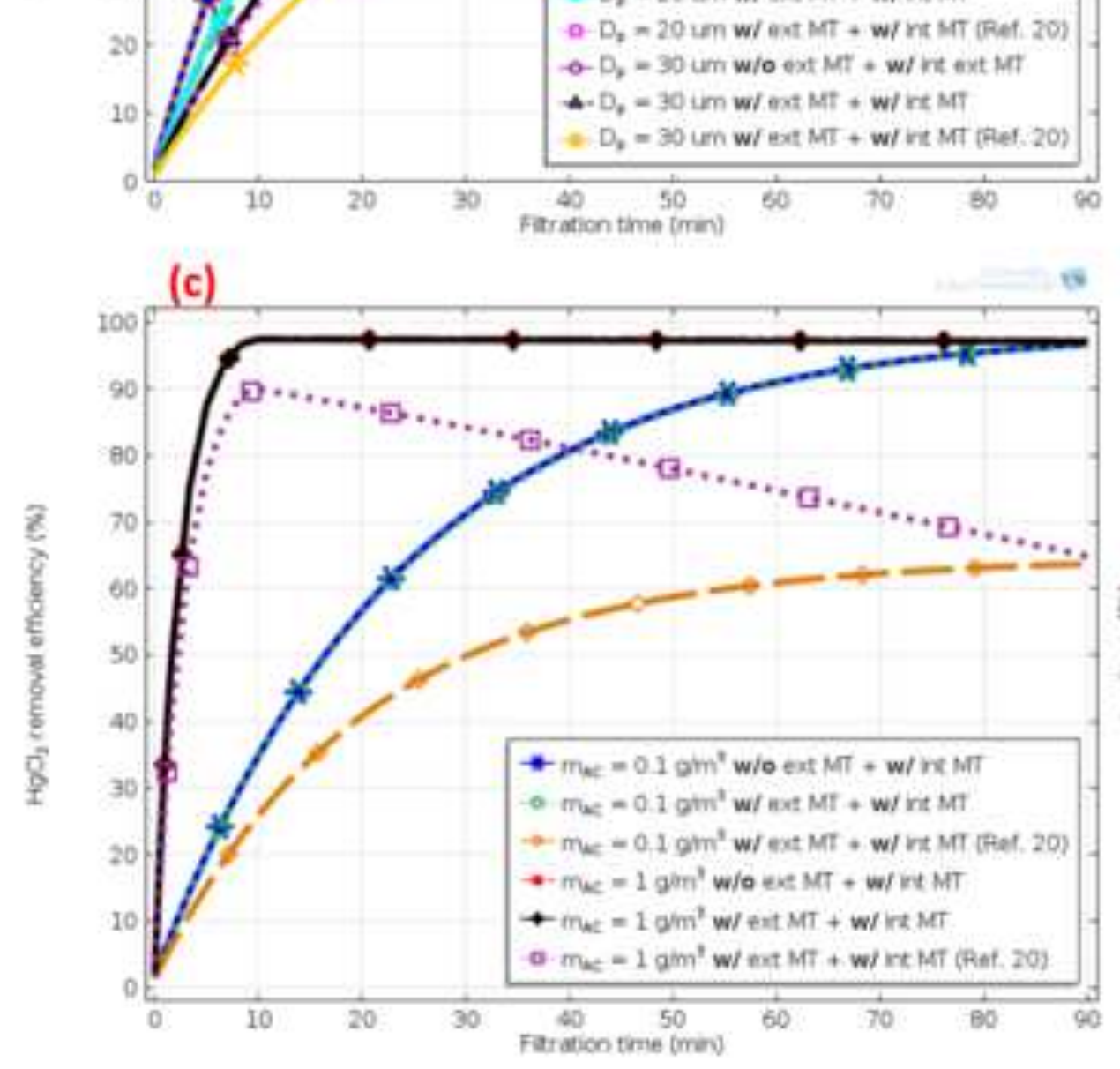

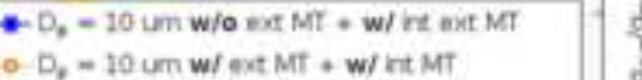

$+D_{1}=20$ um w/ ext MT + wirt MT

$-0-D_{1}=30$ um w/o ext Mt + w/ ht ext MIt

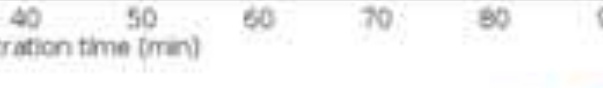

(b)

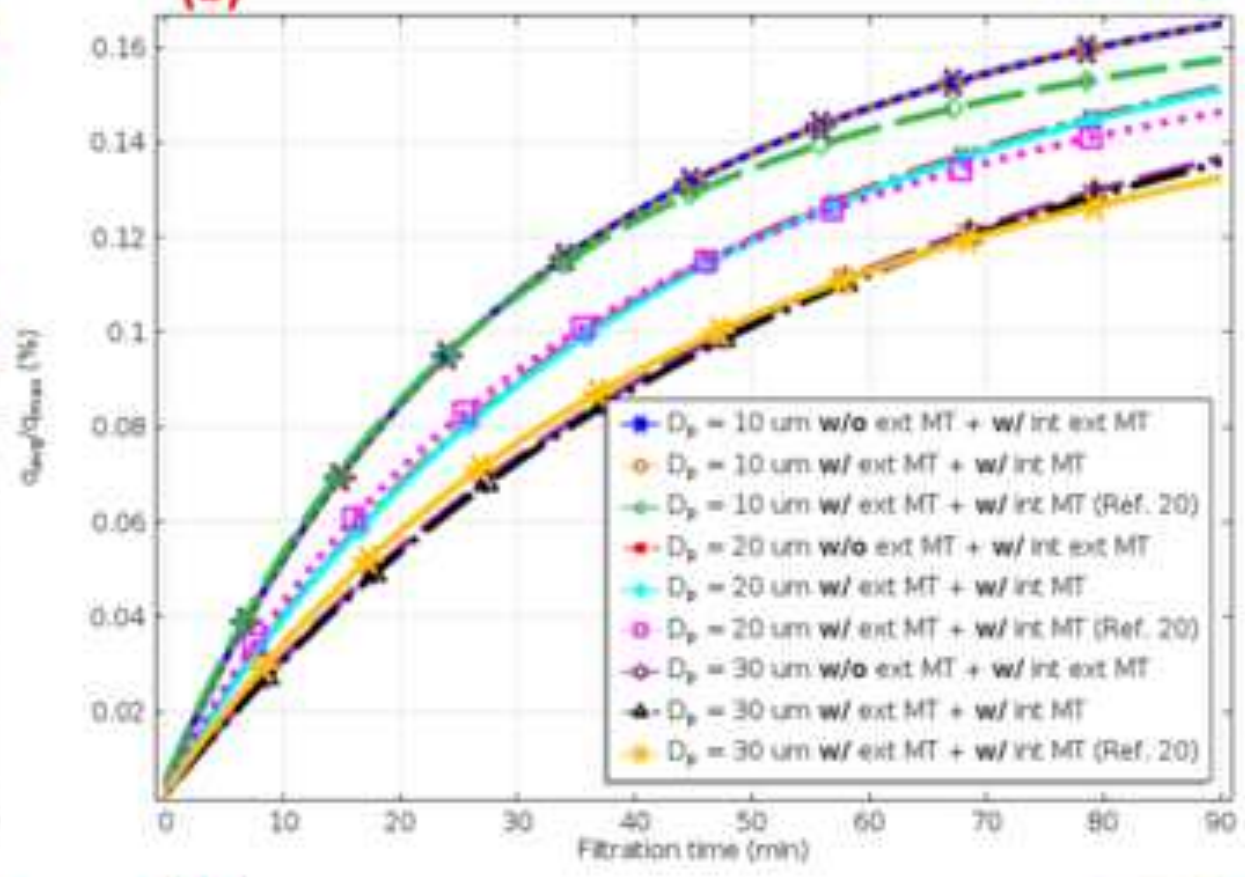

(d)

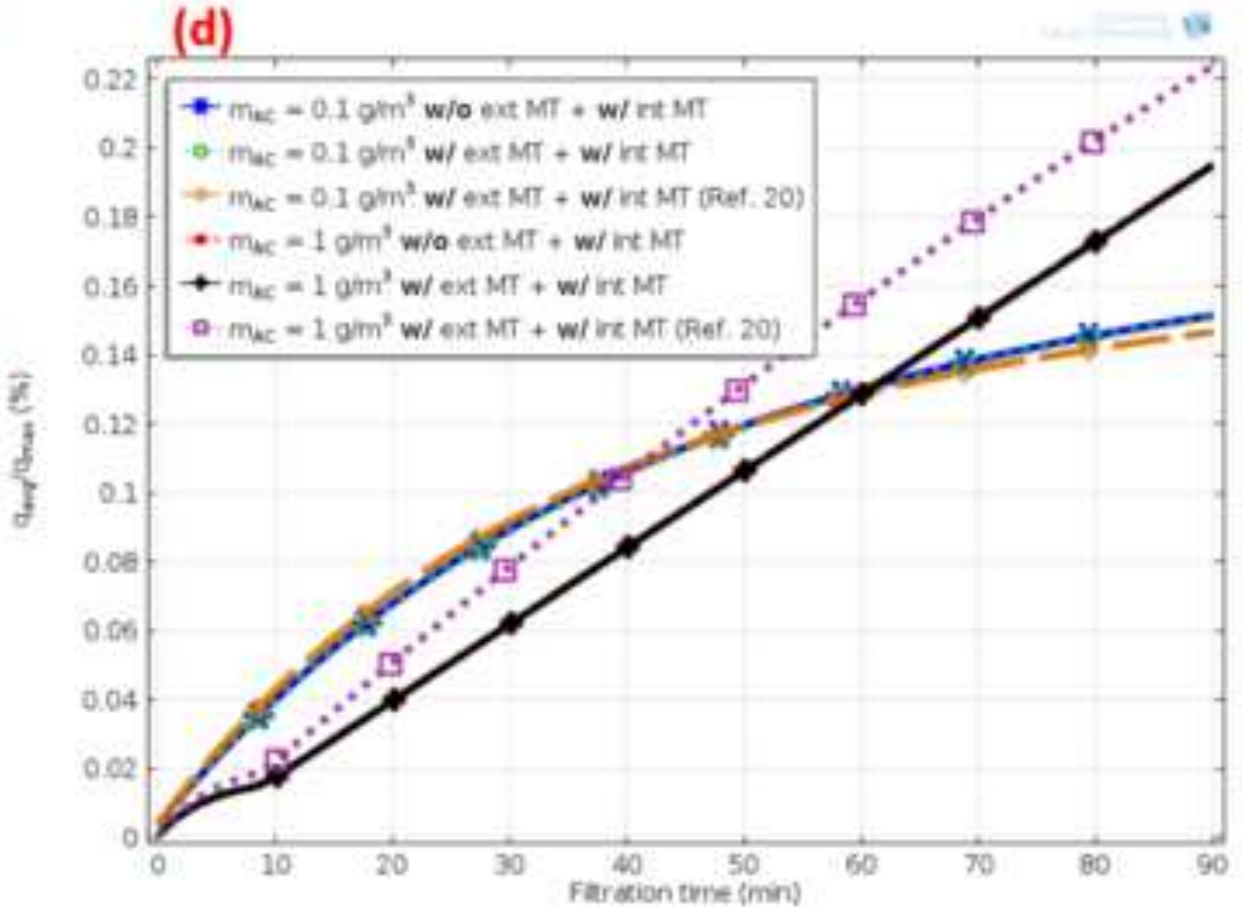

a 
(a)

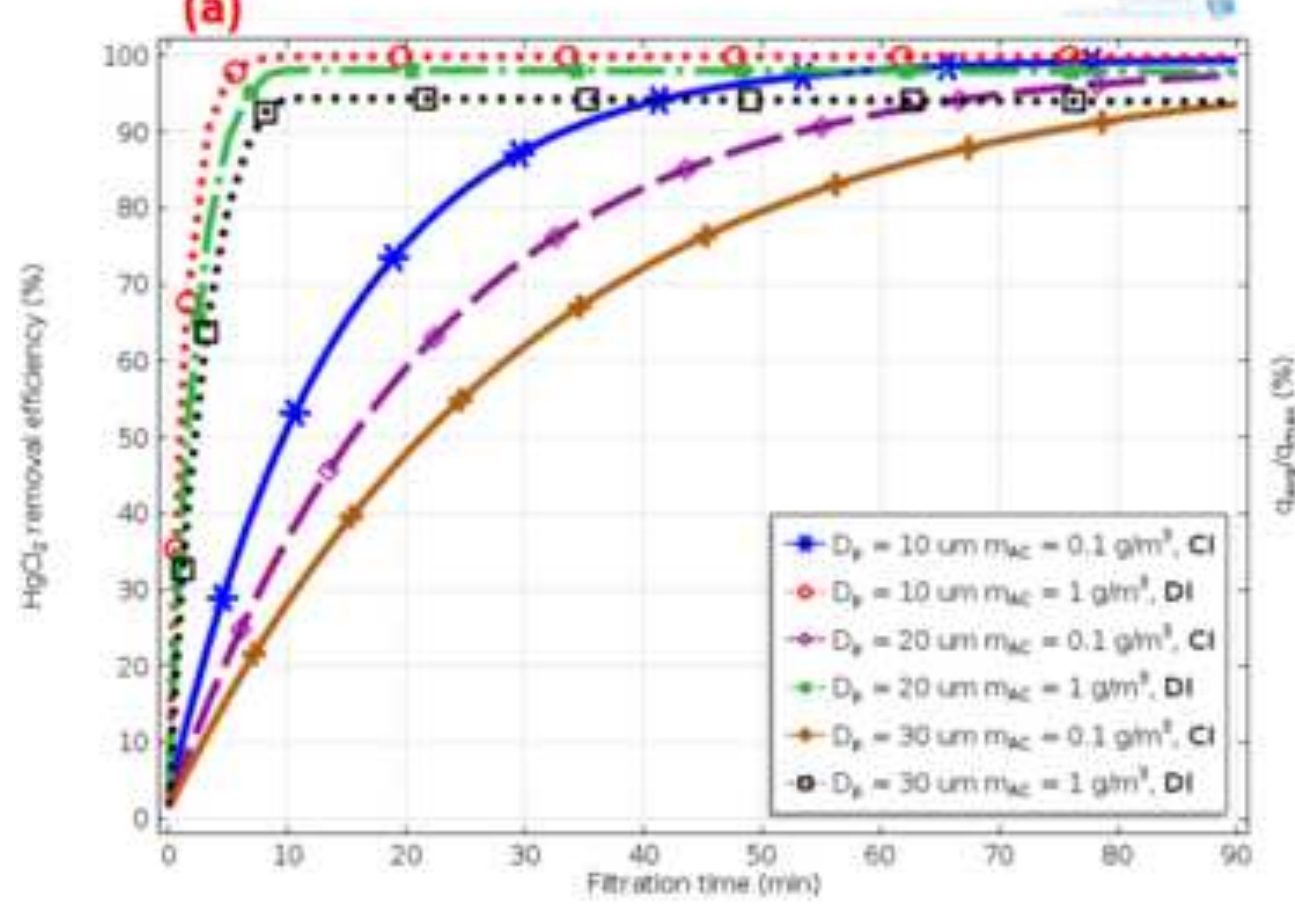

(b)

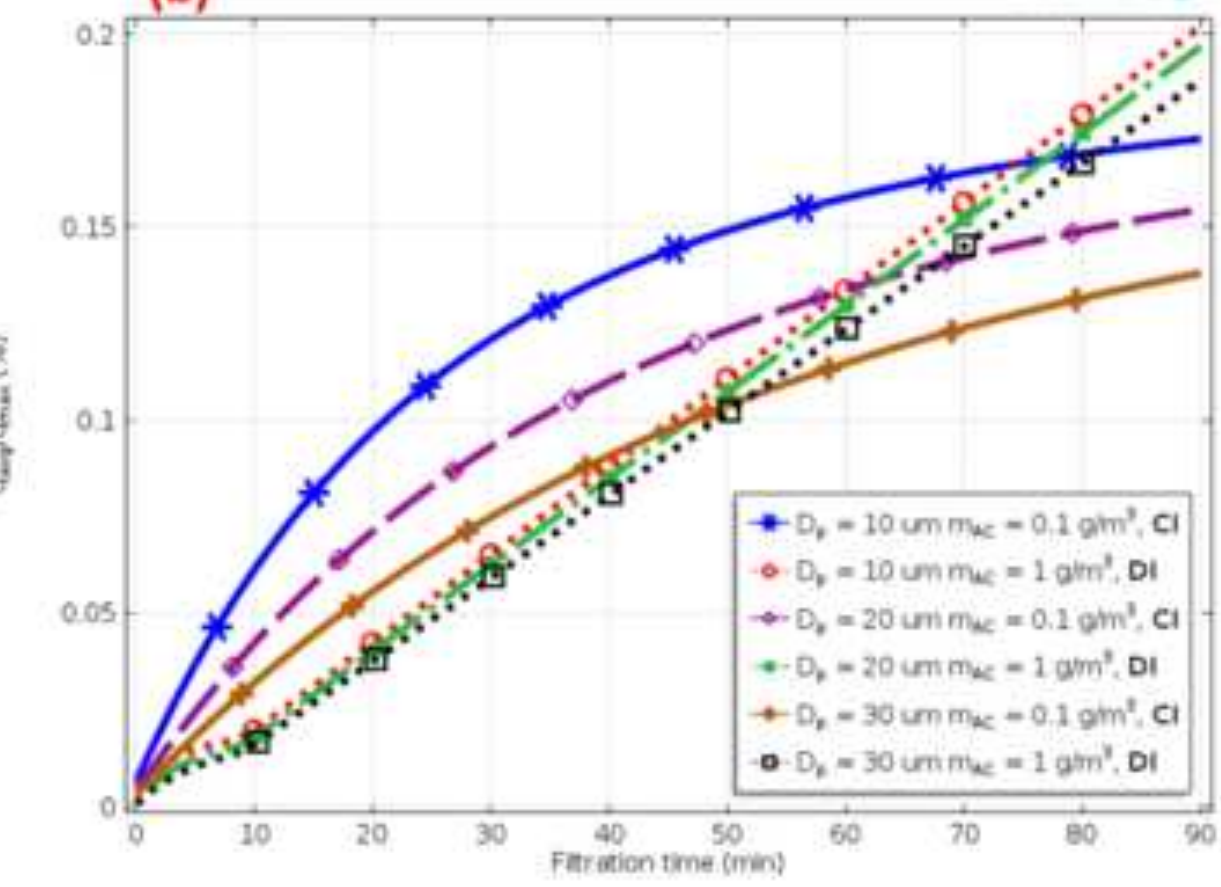




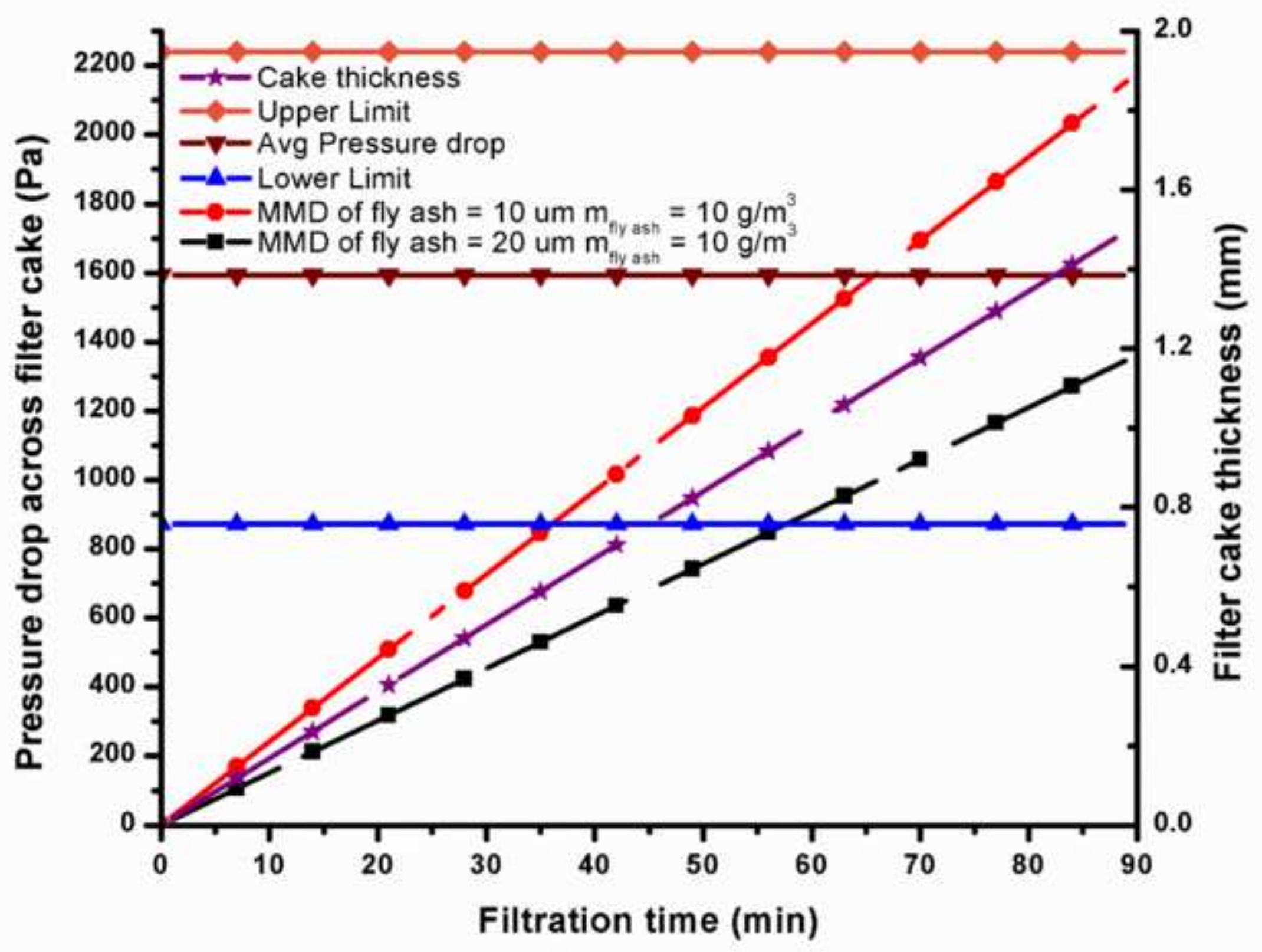

